\title{
Development of precipitation retrievals at millimeter and sub-millimeter wavelengths for geostationary satellites
}

\author{
E. Defer, ${ }^{1}$ C. Prigent, ${ }^{1}$ F. Aires, ${ }^{2}$ J. R. Pardo,${ }^{3}$ C. J. Walden, ${ }^{4}$ O.-Z. Zanife, ${ }^{5}$ \\ J.-P. Chaboureau, ${ }^{6}$ and J.-P. Pinty ${ }^{6}$ \\ Received 19 March 2007; revised 19 September 2007; accepted 14 December 2007; published 23 April 2008.
}

[1] We study the potential of millimeter and sub-millimeter wavelengths for precipitation retrieval from geostationary sensors based on mesoscale cloud modeling and radiative transfer computation. Hydrometeor profiles simulated with the Meso-NH cloud resolving model for five European midlatitude situations are used to compute the brightness temperatures at frequencies from 23.8 to $875 \mathrm{GHz}$ with the Atmospheric Transmission at Microwaves (ATM). Performances of both rain detection and rain rate retrieval are analyzed for different frequency sets, over ocean and land separately, and compared to the user requirements. The performances of a frequency set such as that already planned for geostationary satellites (with channels in the $\mathrm{O}_{2}$ lines at 50,118, and $424 \mathrm{GHz}$, and in the $\mathrm{H}_{2} \mathrm{O}$ lines at $183,325,380 \mathrm{GHz}$ ) satisfy the requirements for Numerical Weather Prediction and NoWCasting in terms of rain detection as well as for rain rate retrieval above $1 \mathrm{~mm} / \mathrm{h}$. Suppressing the $50 \mathrm{GHz} \mathrm{O}$ channels does not seriously degrade the performances, except for rain rate below $1 \mathrm{~mm} / \mathrm{h}$, and, in addition, limits the spatial resolution problem from a geostationary orbit. Adding the thermal infrared observations has a limited impact. The retrieval of other hydrometeor quantities (cloud, ice) is also tested as well as the possibility to retrieve rain and the other hydrometeor profiles. These theoretical results are evaluated at close-to-millimeter wavelengths with coincident AMSU-B and radar observations (BALTEX and CAMRa). The results are degraded with respect to the theory, as expected, but are consistent with the observations.

Citation: Defer, E., C. Prigent, F. Aires, J. R. Pardo, C. J. Walden, O.-Z. Zanifé, J.-P. Chaboureau, and J.-P. Pinty (2008), Development of precipitation retrievals at millimeter and sub-millimeter wavelengths for geostationary satellites, J. Geophys. Res., 113, D08111, doi:10.1029/2007JD008673.

\section{Introduction}

[2] Precipitation is characterized by a high variability in space and time and, as a consequence, both high spatial resolution and temporal sampling are required to obtain a realistic estimate of the rainfall intensity and distribution at a global scale. Rain gauge measurements are relatively scarce and are not well distributed over the globe, especially over oceans. Increasing national and international radar

\footnotetext{
${ }^{1}$ Laboratoire d'Etudes du Rayonnement et de la Matière en Astrophysique, Centre National de la Recherche Scientifique, Observatoire de Paris, Paris, France.

${ }^{2}$ Laboratoire de Météorologie Dynamique, Institut Pierre-Simon Laplace/Centre National de la Recherche Scientifique, Université de Paris VI/ Jussieu, Paris, France.

${ }^{3}$ Instituto de Estructura de la Materia - Departamento de Astrofisica Molecular e Infrarroja, CSIC, Madrid, Spain.

${ }^{4}$ Space Science and Technology Department, Rutherford Appleton Laboratory, Chilton, Didcot, UK.

${ }^{5}$ Collecte Localisation Satellite, Ramonville Saint-Agne, Toulouse, France.

${ }^{6}$ Laboratoire d'Aérologie, Université de Toulouse, Centre National de la Recherche Scientifique, Toulouse, France.
}

Copyright 2008 by the American Geophysical Union. 0148-0227/08/2007JD008673 networks provide high temporal sampling of rain rates essentially over land but the spatial coverage in terms of global precipitation estimates is still poor. Space-borne remote sensing of precipitation is a solution, provided that both high spatial resolution and very rapid revisiting time can be achieved. The needs for precipitation observations were recently assessed by a EUMETSAT expert group [Rizzi et al., 2006] and are presented in Table 1 (another document [Golding et al., 2001] specifies the user requirements for nowcasting and very short range forecasting but it is less detailed in terms of precipitation and the requirements are all less stringent.) They cover meteorological applications, both Numerical Weather Prediction (NWP) and NoWCasting (NWC), as well as hydrology and climate for 2020 onwards. Currently, precipitation observations are not systematically assimilated in NWP systems and the report underlines that precipitation information will become increasingly important to improve forecast in NWP and in NWC applications related to severe weather events.

[3] Contrarily to infrared and visible observations, microwave measurements show a more direct relation with precipitation, especially at frequencies below $30 \mathrm{GHz}$. The success of the Tropical Rainfall Measuring Mission (TRMM), equipped with both precipitation radar at 
Table 1. User Requirement Table Related to Liquid Precipitation in Terms of Accuracy, Based on the EUMETSAT Position Paper [Rizzi et al., 2006]

\begin{tabular}{|c|c|c|c|c|c|}
\hline \multirow[b]{2}{*}{ Parameter } & \multirow[b]{2}{*}{ Application } & \multicolumn{4}{|c|}{ Accuracy, RMS } \\
\hline & & Unit & Threshold & Breakthrough & Objective \\
\hline \multirow[t]{2}{*}{ Precipitation profile (liquid) } & NWP global & $\%$ & 100 & 50 & 20 \\
\hline & NWP regional & $\%$ & 100 & 50 & 20 \\
\hline \multirow[t]{6}{*}{ Precipitation rate at surface (liquid) } & NWP global & $\%$ & 100 & 50 & 20 \\
\hline & NWP regional & $\%$ & 100 & 50 & 20 \\
\hline & climate & $\mathrm{mm} / \mathrm{h}$ & 10 & 5 & 2 \\
\hline & hydrology (>10 mm/h) & $\%$ & 20 & 10 & 5 \\
\hline & hydrology $(1-10 \mathrm{~mm} / \mathrm{h})$ & $\%$ & 40 & 20 & 10 \\
\hline & hydrology $(<1 \mathrm{~mm} / \mathrm{h})$ & $\%$ & 80 & 40 & 20 \\
\hline \multirow[t]{3}{*}{ Precipitation detection (liquid) } & NWP global & HR/FAR & $50 / 50$ & $95 / 10$ & $99 / 2$ \\
\hline & NWP regional & HR/FAR & $50 / 50$ & $95 / 10$ & $99 / 2$ \\
\hline & NWC & HR/FAR & $50 / 50$ & $70 / 40$ & $85 / 20$ \\
\hline \multirow[t]{3}{*}{ Precipitation Type } & NWP global & classes & 3 & 4 & 6 \\
\hline & NWP regional, NWC & classes & 3 & 4 & 6 \\
\hline & climate & classes & 3 & 4 & 6 \\
\hline
\end{tabular}

$13 \mathrm{GHz}$ and passive microwave radiometer between 10 and $85 \mathrm{GHz}$ demonstrates the ability of this frequency range for precipitation estimation [e.g., Olson et al., 2006; Yang et al., 2006]. However, from low orbits the revisiting time is poor and even a constellation of low orbit satellites such as the Global Precipitation Measurement (GPM) project provides a limited number of overpasses of an area per day ( 8 overpasses per day in the GPM project) [Mugnai, 2003]. Geostationary satellites offer the advantage of a quasicontinuous observation of a large portion of the globe that is adequate for nowcasting or short range forecasting of severe events and for climatological analysis of the full diurnal cycle of precipitation patterns. The major limitation with passive microwave instruments on board geostationary satellites is the difficulty in reaching acceptable spatial resolution with reasonable antenna sizes. The use of higher frequency makes it possible to reduce the antenna aperture for a given size. The NASA-NOAA Geosynchronous Microwave Sounder Working Group developed the project of a sub-millimeter wavelength GEosynchronous Microwave sounder and imager (GEM) equipped with a $2 \mathrm{~m}$ scanning antenna, with channels in the oxygen bands $(54,118$, and $425 \mathrm{GHz})$ and in the water vapor lines (183 and $340 /$ $380 \mathrm{GHz}$ ) [Staelin et al., 1998]. The Geostationary Observatory for Microwave Atmospheric Sounding (GOMAS) project was also proposed recently to ESA as a Next Earth Explorer core mission with similar channels but a 3-m filled-aperture antenna, providing a spatial resolution of $37 \mathrm{~km}$ at $118 \mathrm{GHz}$ and $12 \mathrm{~km}$ at $380 \mathrm{GHz}$ [Bizzari et al., 2005]. The Geostationary Synthetic Thinned Aperture Radiometer (GeoSTAR) on the upcoming GOES-R mission [Lainbrigtsen et al., 2004] will use an aperture synthesis approach to sound the atmosphere at 50 and $183 \mathrm{GHz}$ and to provide data products such as rain rate with a $25-\mathrm{km}$ spatial resolution. Both GOMAS and GEM satellite projects recognize the importance of millimeter and sub-millimeter wavelength observations for cloud and precipitation characterization from geosynchronous orbits. However, there have been very few studies dedicated to precipitation retrieval in this wavelength range. It is the goal of this study to analyze the potential of millimeter and sub-millimeter observations for precipitation detection and retrieval.
[4] Meteorological satellites today, in low or high orbits, do not provide observations at frequencies above $190 \mathrm{GHz}$. Although aircraft measurement campaigns have been conducted at millimeter frequencies above ice clouds, precipitating cases were not specifically explored [Evans et al., 2005]. As a consequence, the feasibility of rain retrieval at millimeter wavelengths can only be tested from radiative transfer simulations. Measurements in the millimeter wavelength range are not expected to directly sense the rain profile close to the ground. At these frequencies, cloud opacity in the precipitating areas will drastically limit the amount of upwelling radiation emitted or scattered by rain. Potential correlations between precipitation and millimeter wavelength observations are expected to arise from indirect relationships between the cloud microphysics and the precipitation down below. It is thus very important that the simulated atmospheric and hydrometeor profiles reproduce as accurately as possible the whole atmospheric column in the precipitating situations. The potential of the millimeter wavelength observations for precipitation retrieval will be analyzed using statistical methods. The quality of the statistical data set is essential: The variability described in the data set should represent as correctly as possible the different regimes of precipitation in the region of interest. This study focuses on European meteorological situations, with special attention to the user requirements specified by EUMETSAT. The simulations are generated from realistic mesoscale atmospheric outputs representative of European situations, from stratiform to convective precipitations. The mesoscale cloud model outputs are coupled to an up-to-date radiative transfer model to provide a realistic simulated data set, generated for a large range of frequencies, from microwave to sub-millimeter wavelengths. It complements the previous work by Mech et al. [2007], with special emphasis on the rain detection, development and comparison of different retrieval schemes for integrated quantities as well as profiles, and comparisons between radar rain estimates and satellite retrievals from close-to-millimeter observations. The methodology is described in section 2. The results of the precipitation detection and rain rate retrieval are presented in section 3 for the various frequency sets, along with results about cloud characterization and rain profiling. Systematic comparisons with IR simulations are 
also performed to assess how the two wavelength ranges complement one another. In section 4 , the rain detection and retrieval algorithms are tested at close-to-millimeter wavelengths, using collocated AMSU-B and radar observations over the south of England (the Chilbolton CAMRa radar) and the Baltic region (BALTEX radars).

\section{The Methodology}

[5] The present article synthesizes the results of the last stage of a three-step study. The first step consists in performing realistic cloud simulations with a cloud model [Chaboureau et al., 2008]. The second step described by Meirold-Mautner et al. [2007] deals with the computation of brightness temperatures at different frequencies with the help of a radiative transfer model. Meirold-Mautner et al. [2007] present results of a detailed investigation of the importance of the representation of the microphysics for the radiative transfer calculations. Meirold-Mautner et al. [2007] also show that the simulated brightness temperatures as computed from the outputs of the cloud model show consistent behaviors compared to concurrent observations at frequencies below $190 \mathrm{GHz}$. The present article assesses the ability of different frequency sets to detect rain and quantify the rain rate from the merging of the microphysics data set and the associated brightness temperature database. In the following section, we describe the microphysics/brightness temperature database and both classification and retrieval methods while results are discussed in the next section.

\subsection{The Database of Atmospheric Profiles and the Associated Tbs}

\subsubsection{Mesoscale Cloud Simulations}

[6] In order to study midlatitude cases, a database of five European meteorological situations are selected that represent a large variety not only in rain rate distribution but also in terms of precipitation nature: Cyclonic systems, stratiform cases, as well as the millenium storm in the UK with very high rain rates. The cloud-resolving model Meso-NH is used to provide a detailed description of the atmosphere including the hydrometeor distribution of five hydrometeor types (rain, cloud, ice, graupel, and snow) [Lafore et al., 1998].

[7] Chaboureau et al. [2008] describe the setup of the cloud simulations as well as the different processes implemented in the cloud model, detail cloud and precipitation variability of the cloud simulations and show that the midlatitude database is complementary to the Goddard PROFiling (GPROF) database [Kummerow et al., 2001; Olson et al., 2006]. (The GPROF database, that is used to develop the retrieval algorithms for TRMM, focuses on Tropical situations, with outputs from 7 cases [Kummerow et al., 2001].) The cloud simulations were performed with a two-way grid nesting technique [Stein et al., 2000] with a 50 -layer configuration and with a depth of the vertical grid ranging from 60 to $600 \mathrm{~m}$. Each meteorological situation covers roughly a region of $1600 \mathrm{~km} \times 1600 \mathrm{~km}$ and for each situation two time steps representative of the evolution of the situations are available.

[8] The cloud simulations are performed with an explicit microphysics scheme while hydrometeor size distributions for the 5 species are assumed to follow a generalized $\gamma$-law as detailed by Chaboureau et al. [2008]. Different studies have been carried out to assess the Meso-NH cloud model scheme such as comparisons with METEOSAT [Chaboureau et al., 2000, 2002], TRMM Microwave Imager [Wiedner et al., 2004], SSMI and AMSU [Meirold-Mautner et al., 2007] or radar [Richard et al., 2003] observations. Those studies at various wavelengths in many investigations show that neither strong nor systematic deficiencies in the microphysical scheme on the prediction of the precipitating hydrometeor contents are present. Recently, a model intercomparison exercise has further shown that Meso-NH as well as other state-of-the-art non-hydrostatic models perform better in forecasting rain than operational models [Richard et al., 2007]. The large spread in precipitation found between the non-hydrostatic models recalls however the uncertainty still inherent in cloud microphysics schemes.

\subsubsection{The Radiative Transfer Code}

[9] Simulations from the cloud model are used as inputs to the radiative transfer model Atmospheric Transmission at Microwaves (ATM) developed by Pardo et al. [2001]. This model includes an up-to-date gaseous absorption scheme validated up to frequencies of 1.6 THz [Pardo et al., 2005] and radiation scattering by oblate or prolate spheroids is calculated with T-matrix algorithms [Mishchenko et al., 2000]. The emissivity of the wind-roughened ocean surface is calculated using Guillou et al. [1996]. The land surface emissivity is estimated from atlases derived from SSM/I observations [Prigent et al., 2008]. Multiple scattering calculations are based on the adding-doubling method and originate from Evans and Stephens [1995]. Interpretation of the Meso-NH outputs in terms of radiative transfer properties is not always straightforward and sources of uncertainties include the estimation of particle density (consequently the refractive index) and shape.

\subsubsection{Sensitivity of the Radiative Transfer Simulations} to the Hydrometeor Characteristics

[10] Meirold-Mautner et al. [2007] study the sensitivity of the microwave simulations to the hydrometeor properties for the present database and discuss the importance of a correct representation of the snow in midlatitude clouds in a radiative point of view. Meirold-Mautner et al. [2007] also detail the potential sources of uncertainty associated with the microphysical scheme and the different properties of the particles (density, refractive index, shape).

[11] The radiative computation performed in the present study uses the cloud content provided by the cloud model on a $10-\mathrm{km}$ grid. It is assumed that the microphysics is spatially uniformly distributed over each grid point. In order to sense the impact of the non-uniform beam filling effect on the retrieval performances further studies should be performed at higher cloud resolution convoluted with the footprints at the specified frequencies.

\subsubsection{Evaluation of Meso-NH / ATM Combination With Satellite Observations up to $190 \mathrm{GHz}$}

[12] Since the quality of statistical retrieval algorithms is directly related to the realism of the simulated database, it is crucial to evaluate the quality of the simulations. Given that the Meso-NH calculations correspond to real atmospheric situations, comparisons have been performed between Meso-NH / ATM simulations and satellite observations at frequencies up to $190 \mathrm{GHz}$ using the Special Sensor Microwave /Imager (between 19 and $85 \mathrm{GHz}$ ) and AMSU 
Table 2. List of the Simulated Frequencies and Associated Noise Level

\begin{tabular}{ll}
\hline \multicolumn{1}{c}{ Frequencies $(\mathrm{GHz})$ or Wavelengths $(\mu \mathrm{m})[$ noise $($ in $\mathrm{K})]$} & \multicolumn{1}{c}{ Characteristics } \\
\hline $23.8[0.2], 31.4[0.27]$ & low frequency windows \\
$50.3[0.22], 52.8[0.15], 53.596 \pm 0.115[0.15], 54.40[0.13], 54.94[0.14], 55.50[0.14]$ & $\mathrm{O}_{2}$ line $50 \mathrm{GHz}$ \\
$89.0[0.37], 150.0[0.84]$ & medium frequency windows \\
$183.31 \pm 1[1.06], 3[0.7], 7[0.6]$ & $\mathrm{H}_{2} \mathrm{O}$ line $183 \mathrm{GHz}$ \\
$220.5[1.0], 301.0[1.0], 462.5[1.0], 684.0[1.0], 875.0[1.0]$ & high frequency windows \\
$118.75 \pm 0.2[0.5], 0.4[0.5], 0.7[0.5], 1.1[0.4], 1.5[0.4], 2[0.3], 3[0.2]$ & $\mathrm{O}_{2}$ line $118 \mathrm{GHz}$ \\
$325.15 \pm 0.5[1.0], 2[1.0], 7[0.9], 25[0.9]$ & $\mathrm{H}_{2} \mathrm{O}$ line $325 \mathrm{GHz}$ \\
$380.19 \pm 0.5[0.5]$ & $\mathrm{H}_{2} \mathrm{O}$ line $380 \mathrm{GHz}$ \\
$424.76 \pm 0.3[0.5], 0.6[0.5], 1[0.5], 1.5[0.4], 2[0.4], 4[1]$ & $\mathrm{O}_{2}$ line $424 \mathrm{GHz}$ \\
11 & thermal IR \\
\hline
\end{tabular}

(between 22 and $190 \mathrm{GHz}$ [Meirold-Mautner et al., 2007]. Such a comparison for a large range of frequencies is very challenging: Each frequency is sensitive to a large set of atmospheric and surface parameters, imposing very strong constraints on the quality of both the Meso-NH simulations and the radiative transfer calculations. SSM/I frequencies are more sensitive to the lower part of the atmospheric column, including the surface contribution. The AMSU-B window channel at $150 \mathrm{GHz}$ is particularly responsive to scattering by frozen particles. In addition, IR responses have been simulated with RTTOV87 [Saunders et al., 2005] and compared to the METEOSAT images [Chaboureau et al., 2008]: This helps in distinguishing the errors of the radiative transfer model from those of the cloud model because the radiative transfer model used for the IR has been developed independently from the one used at microwaves. The comparisons show an overall good agreement between the simulations and the observations but first revealed an underestimation of the scattering by frozen particles at microwaves above $80 \mathrm{GHz}$ (especially at $150 \mathrm{GHz}$ ). A careful analysis made it possible to overcome the discrepancy, by defining more accurately the scattering properties of snow in the cloud [Meirold-Mautner et al., 2007].

\subsubsection{Frequency Selection}

[13] Satellite projects in the millimeter and sub-millimeter wavelengths such as GEM and GOMAS on geostationary orbits or Cloud Ice Water Sub-millimeter Imaging Radiometer (CIWSIR) on a polar orbit [Buehler et al., 2005] propose frequency channels that have similarities but are not identical, mainly because their objectives are not exactly the same: The first two (GEMS and GOMAS) being originally focused on water vapor and temperature profiling and more recently on precipitation, and the last one (CIWSIR) on cirrus characterization. The relationships between the frequency responses and the hydrometeor profiles are complex, non-linear, and regime dependent. In the present study simulations are performed at a large number of frequencies, in window channels as well as in water vapor and oxygen lines (Table 2), covering the frequency range from $20 \mathrm{GHz}$ to $900 \mathrm{GHz}$. Channels around the 183, 325, and $380 \mathrm{GHz}$ water vapor lines can provide water vapor profile information, whereas the channels around 50,118, and $424 \mathrm{GHz}$ in the $\mathrm{O}_{2}$ lines give access to the atmospheric temperature profile [Klein and Gasiewski, 2000; Prigent et $a l ., 2006]$. In addition to their water vapor and temperature profiling capabilities, these sounding channels are expected to constrain the hydrometeor profiles [Bauer and Mugnai, 2003]. A total of 37 frequencies, including the AMSU and the 11- $\mu \mathrm{m}$ thermal IR channels, have been simulated for all the profiles in the database (Table 2). Simulations at SSMI frequencies were also performed [Meirold-Mautner et al., 2007] but are not used in the present study. Various channel combinations are tested and compared for their potential to detect rain and estimate the rain rate. Table 3 lists the frequency sets investigated in this study. The F07 set is of special importance in this study as it is close to the frequencies suggested for the GEOstationary project GOMAS. The F09 is close to the channel selection for CIWSIR in Low Earth Orbit.

\subsubsection{The Resulting Database}

[14] Simulations for each frequency are performed for 9 different incidence angles $(0,9,19,30,40,52,63,74$, and $85^{\circ}$ ). The two orthogonal linear polarizations are calculated separately and are combined as in the AMSU cross-track scanner [Saunders, 1993]. From a geostationary orbit, the polarization combination will also depend upon the scanning angle and the areas in satellite coverage. In this study, polarization emanates essentially from the surface as the hydrometeors are assumed to be spherical. Scatteringinduced polarization can be generated by oriented nonspherical hydrometeors [Prigent et al., 2005] but given the lack of information concerning the particle shapes and orientations, this effect is not considered here. The initial atmospheric profile database consists of a pixel population of $48 \%$ over land, $40 \%$ over ocean and $12 \%$ over the coasts. Note that in this work, coastal pixels are ignored. The entire database consists of 10 situations ( 2 outputs from the simulation of 5 meteorological situations) with 157 (6 parameters (rain, cloud, ice, graupel, snow and water vapor) $\times 25$ layers +6 integrated quantities (rain, cloud, ice, graupel, snow and water vapor) + rain rate) cloud and rain parameters and 325 ( 9 angles $\times 36$ microwave channels +1 IR channel) brightness temperatures for each profile.

[15] For a careful comparison of the retrieval potential over land and ocean and to double the database, two different simulations are performed for each frequency and atmospheric profile, one with the surface emissivity corresponding to the exact location, and the other one with an emissivity corresponding to the opposite surface type (land becoming ocean and vice versa). In the second simulation, the realism is maintained by using the same Meso-NH surface temperature, the Meso-NH surface wind speed (in case of ocean calculation) and a land emissivity estimate in a nearby location at the same latitude for the land cases. Figure 1 presents the distribution of the rain rate 
Table 3. Frequency Combinations Investigated in the Present Study

\begin{tabular}{|c|c|c|c|c|c|c|c|c|c|}
\hline $\begin{array}{l}\text { Frequency } \\
\text { Set }\end{array}$ & $\begin{array}{c}\text { Low } \\
\text { Frequency } \\
\text { Window }\end{array}$ & $\mathrm{O}_{2} 50$ & $\begin{array}{l}\text { Medium } \\
\text { Frequency } \\
\text { Window }\end{array}$ & $\mathrm{O}_{2} 118$ & $\mathrm{H}_{2} \mathrm{O} 183$ & $\begin{array}{c}\text { High } \\
\text { Frequency } \\
\text { Window }\end{array}$ & $\begin{array}{c}\mathrm{H}_{2} \mathrm{O} \\
325+380 \\
\end{array}$ & $\mathrm{O}_{2} 424$ & Mission \\
\hline F01 & $X+89$ & $\mathrm{X}$ & & & & & & & AMSU-A \\
\hline F02 & X & $\mathrm{X}$ & $\mathrm{X}$ & & $\mathrm{X}$ & & & & AMSU-AB \\
\hline F03 & & & $\mathrm{X}$ & & $\mathrm{X}$ & & & & AMSU-B \\
\hline F04 & & & $\mathrm{X}$ & & & & & & $89 \& 150$ \\
\hline F05 & & & $\mathrm{X}$ & & $\mathrm{X}$ & $\mathrm{X}$ & & & \\
\hline F06 & & & & & & $\mathrm{X}$ & & & \\
\hline F07 & & $\mathrm{X}$ & & $\mathrm{X}$ & $\mathrm{X}$ & & $\mathrm{X}$ & $\mathrm{X}$ & GEO like \\
\hline F08 & & & & $\mathrm{X}$ & $\mathrm{X}$ & & $\mathrm{X}$ & $\mathrm{X}$ & HF-GEO like \\
\hline F09 & & & & & $\mathrm{X}$ & $\mathrm{X}$ & $\mathrm{X}$ & & LEO like \\
\hline F10 & & & & $\mathrm{X}$ & $\mathrm{X}$ & $\mathrm{X}$ & $\mathrm{X}$ & & LEO like +118 \\
\hline F11 & & & & & $\mathrm{X}$ & & & & \\
\hline F12 & & & & $X$ & $\mathrm{X}$ & & & & \\
\hline F13 & & & & $\mathrm{X}$ & $\mathrm{X}$ & & $\mathrm{X}$ & & \\
\hline F14 & & & & & $\mathrm{X}$ & & $\mathrm{X}$ & & \\
\hline F15 & & & & & $\mathrm{X}$ & & $\mathrm{X}$ & $\mathrm{X}$ & \\
\hline F16 & & & & $\mathrm{X}$ & & $\mathrm{X}$ & $X$ & & \\
\hline F17 & & & & & & $\mathrm{X}$ & $\mathrm{X}$ & $\mathrm{X}$ & \\
\hline F18 & & & & $\mathrm{X}$ & & & & & \\
\hline F19 & & & & $\mathrm{X}$ & & & $\mathrm{X}$ & & \\
\hline
\end{tabular}

for both sea and land pixels, both pixel categories exhibiting now the same rain rate distribution.

[16] The first tests showed that the strong rain rates were not properly retrieved because they were under-represented in the database. To solve this problem, the histogram of the rain rate (Figure 1) was modified to be uniform. For each rain rate (RR) bin of the histogram, randomly selected pixels are duplicated so that the number of samples in each bin becomes identical. Such an operation is a way to force the different retrieval algorithms to be equally sensitive to the entire RR range. In both rain detection and retrieval algorithms, a threshold of $0.1 \mathrm{~mm} / \mathrm{h}$ is set on the rain rate: Below this value, the pixel is rain-free.

\subsection{Classification and Retrieval Methods}

[17] Figure 2 presents the flowcharts of the methodology, that is to build the statistical relationships between rain rate and brightness temperatures (Figure 2a) and then to apply it to observations (Figure 2b). The idea is to design first a rain detection tool and then algorithms to retrieve the rain rate and the hydrometeor distribution along the vertical profile. The rain detection tool, a two-class classification with a $0.1 \mathrm{~mm} / \mathrm{h}$ threshold, identifies the rainy pixels based on their brightness temperatures. The retrieval algorithms are developed for rainy pixels and their associated brightness temperatures. As a consequence, the inversion problem is better constrained: The variability of the brightness temperatures for rainy pixels only is limited as compared to the full extent of their values observable under clear, cloudy and rainy conditions. Two statistical algorithms are tested: A multilinear (ML) regression and a neural network inversion. The problem being complex, non-linear, with a large number of degrees of freedom, the neural network (NN) technique is a natural candidate. Although this work concentrates on precipitation, the objective is not only to retrieve the rain rate but also the full hydrometeor column, including the ice phase.

[18] Situations over land and ocean are treated separately: The surface contributions to the brightness temperatures in the window channels below $150 \mathrm{GHz}$ can be significant and the development of algorithms dedicated to each surface type usually improves the retrieval accuracy. For frequency sets limited to the millimeter and sub-millimeter ranges, the sensitivity to the surface is reduced and the same algorithms could be used, but with restrictions for very dry atmosphere and/or regions with high elevations. The full scheme, including the classification step, is derived for each frequency set (Table 3), each incidence angle, and each surface type, and their performances are compared, for both rain detection and hydrometeor quantification. For the five meteorological situations considered in this study, two model outputs are available [Chaboureau et al., 2008]: The first one is used for the training of the algorithms and the second one is used for testing the algorithms.

\subsubsection{Rain Classification}

[19] The development of a precipitation flag for a given observation is often the first step in a precipitation retrieval. Instead of applying thresholds on selected channels, we suggest the use of a supervised classification method, based on the data set of simulated brightness temperatures and atmospheric profiles used in this work. It allows for the combination of all investigated channels at once to benefit from their synergy, contrarily to threshold methods [e.g., Staelin and Chen, 2000; Chen and Staelin, 2003] that need to discriminate channel by channel. In addition, classifica-

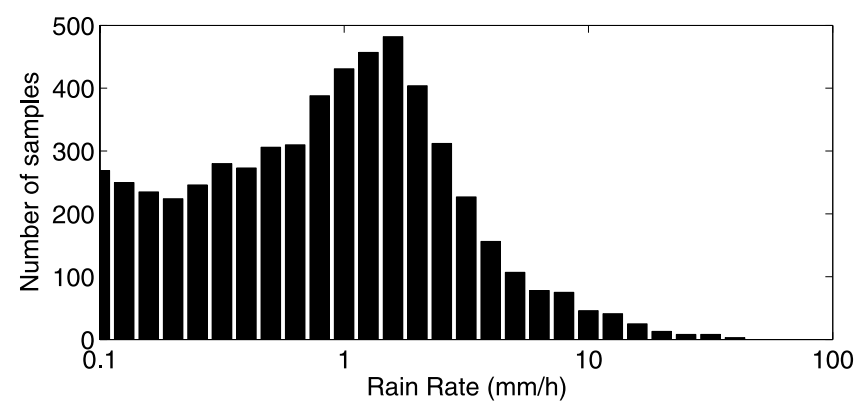

Figure 1. Histogram of the rain rate in the training database for both sea and land pixels. 

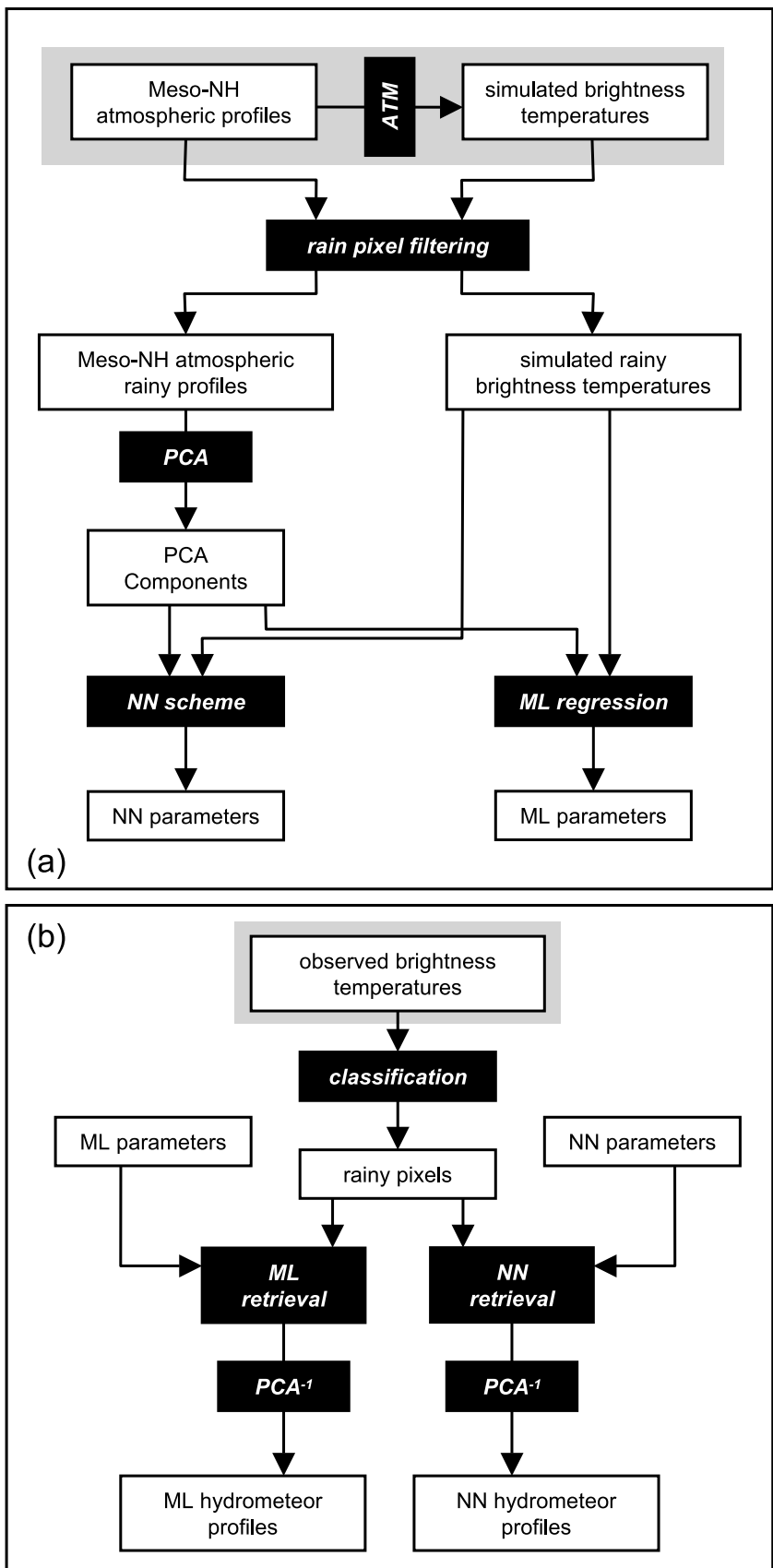

Figure 2. Flowcharts of (a) the building of the relationships and (b) the retrieval methodology.

tions are not limited to the binary precipitation / nonprecipitation flag: Distinction between different precipitation regimes can be derived in order to develop a regimedependent retrieval scheme afterward. Both two-class and multiclass classifications have been tested but the simple binary flag has finally been adopted.

[20] The rain classification is based on a linear method, a standard statistical discriminant analysis tool designed to perform supervised classification [Duda and Hart, 1973]. It reproduces the classification observed in an a priori classified data set of samples. The linear classification estimates the decision boundaries (hyperplanes in the data space) that are optimal, in the least squares sense, for the data set of samples. Contrarily to other discriminant analysis that works with one data dimension at a time (e.g., decision trees), the linear classification is performed in the multivariate data space, which makes it relatively robust to the presence of noise in the data.

[21] To evaluate the classification, the Hit Rate (HR) (also called the Probability Of Detection POD) and the False Alarm Ratio (FAR) are calculated. Table 4 presents the contingency table as used here.

$$
\begin{gathered}
H R=\frac{A}{A+C} \\
F A R=\frac{B}{A+B}
\end{gathered}
$$

\subsubsection{The Rain Retrieval Algorithms}

[22] The database has been carefully analyzed to design an adequate pre-processing step. A Principal Component Analysis (PCA) of the atmospheric profiles is performed in order to compress the information, to reduce its dimension (from the 157 initial variables in each profile) and to regularize the inversion process, which is important in particular for the retrieval of the atmospheric profiles. PCA is a powerful tool to extract uncorrelated pieces of information. Fifty PCA components are considered, representing $99 \%$ of the variance of the training database.

[23] The database of the selected PCA components and their associated brightness temperatures is then used to train two statistical (Multi-Linear (ML) and Neural Network $(\mathrm{NN})$ ) algorithms (Figure 2a). The standard ML method is a particular case of the NN regression: It is compared here to illustrate the advantages brought by the non-linear scheme (e.g., better treatment of the saturation effects and the interactions between the satellite observations). The NN model that is used is a Multi-Layer Perceptron [Rumelhart et al., 1986] trained by the back-propagation gradient descent algorithm.

\subsubsection{Evaluation of the Retrieval Schemes}

[24] The next step consists of testing the algorithms and determining their performances. The testing database (i.e., the portion of the database that has not been used for the training) is used to evaluate the inversion. For a given set of brightness temperatures, the corresponding algorithm is applied to estimate the hydrometeor quantities in the PCA basis, which are then projected into the initial atmospheric domain by applying the inverse PCA function. For physical parameters showing a large variability such as the rain rate, the sensitivity of the results to the error metric is large and requires a clear definition. In order to quantify the error between the true value $x_{i}$ and the retrieved value $r_{i}$ for each geophysical parameter, we compute the mean absolute relative error $e_{m}$ as defined in equation (3). A second metric to measure the error is used for comparison with the thresholds discussed in the EUMETSAT position paper (and listed in Table 1). The metric $e_{r m s}$ (equation (4)) corresponds to the RMS of the relative error and includes both the random component and the bias error: This is the 
Table 4. Definition of the Contingency Table

\begin{tabular}{lcc}
\hline & Rainy Pixels & Non-Rainy Pixels \\
\hline Classified as rainy pixels & $\mathrm{A}$ & $\mathrm{B}$ \\
Classified as non-rainy pixels & $\mathrm{C}$ & $\mathrm{D}$ \\
\hline
\end{tabular}

accuracy criterion usually used in operational meteorological applications. Both $e_{m}$ and $e_{r m s}$ are computed per RR range in order to assess the changes in the retrieval performances as a function of the rain rate.

$$
\begin{gathered}
e_{m}=\frac{1}{N} \sum_{i=1}^{N} \frac{\left|r_{i}-x_{i}\right|}{x_{i}} \\
e_{r m s}=\sqrt{\frac{1}{N} \sum_{i=1}^{N}\left(\frac{r_{i}-x_{i}}{x_{i}}\right)^{2}}
\end{gathered}
$$

To summarize, for each frequency set, each observing incidence angle and each surface type (land and ocean), a rain detection scheme is developed, along with two statistical retrieval schemes (multilinear and neural network algorithms) that estimate simultaneously the integrated contents of the five studied hydrometeor classes, as well as their vertical distribution. In the following sections, the rain detection and the rain rate retrievals are evaluated and compared for the various situations. The characterization of the derived ice microphysics is briefly discussed as well as the capability of retrieving rain profiles.

[25] Given the large range of tested configurations (frequency combinations, angles, surface types, retrieval methods, retrieved variables) all the results will not be systematically presented. In the following, we try to illustrate the major conclusions and to provide a synthetic analysis of these results, focusing on the rain estimates.

\subsubsection{Impact of the Noise on the Classification and the Rain Rate Retrieval}

[26] Realistic instrument noises have been added to the simulated brightness temperatures. The applied noises follow Gaussian laws with standard deviations that depend upon the frequency (Table 2). For AMSU frequencies, the noise figures are taken from Saunders [1993], while the noise levels for frequencies related to GOMAS are derived from the required values listed by Bizzari et al. [2002], which are in most cases higher than the expected noise values. Three noise configurations have been tested: One without any noise, one with the standard deviation set to the values of Table 2, and finally one with twice the noise from Table 2.

\section{Classification Results}

[27] First, the rain classification is evaluated, for the different frequency combinations, over land and ocean. Figure 3 presents the results of the classification for two original scenes (a cold front (Figure 3a) and a storm over England (Figure 3b)) in the database using AMSU-AB frequencies (F02) for a fixed incidence angle $\left(19^{\circ}\right)$, with no noise added to the simulations. For both scenes, the spatial structures of the rainy regions are well captured, and although two different classifications are used above ocean and land, there is no discontinuity at the transition between the two surface types. For the case that is mainly located over land (Figure 3a), most of the misclassified pixels are situated at the edges of the system. For the second case where most of the pixels are located over the Atlantic Ocean (Figure $3 \mathrm{~b}$ ), the misclassified pixels are predominantly located on the north-eastern part of the scene while nearby the main front the classification performs well, although some non-rainy pixels on the front of the system have been misclassified as rainy pixels.

[28] For the 19 different frequency sets, Figure 4 presents the scores of the classifications for the same incidence angle $\left(19^{\circ}\right)$. Frequency sets presented in Figure $4 \mathrm{a}$ are identical to the ones listed in Table 3. The HR and FAR breakthrough thresholds are indicated, for NWP regional and global applications (95\% and 10\% respectively) and for nowcasting $(70 \%$ and $40 \%)$. Results are plotted with overlaid bars in black for noise-free, in gray for 1-sigma noise and white for 2 -sigma noise. As expected the classifications are less performant (lower HR, higher FAR) when the noise increases. For nowcasting applications that are of primary concern from a geostationary orbit, the FAR is usually well below the breakthrough threshold and the HR is close to it
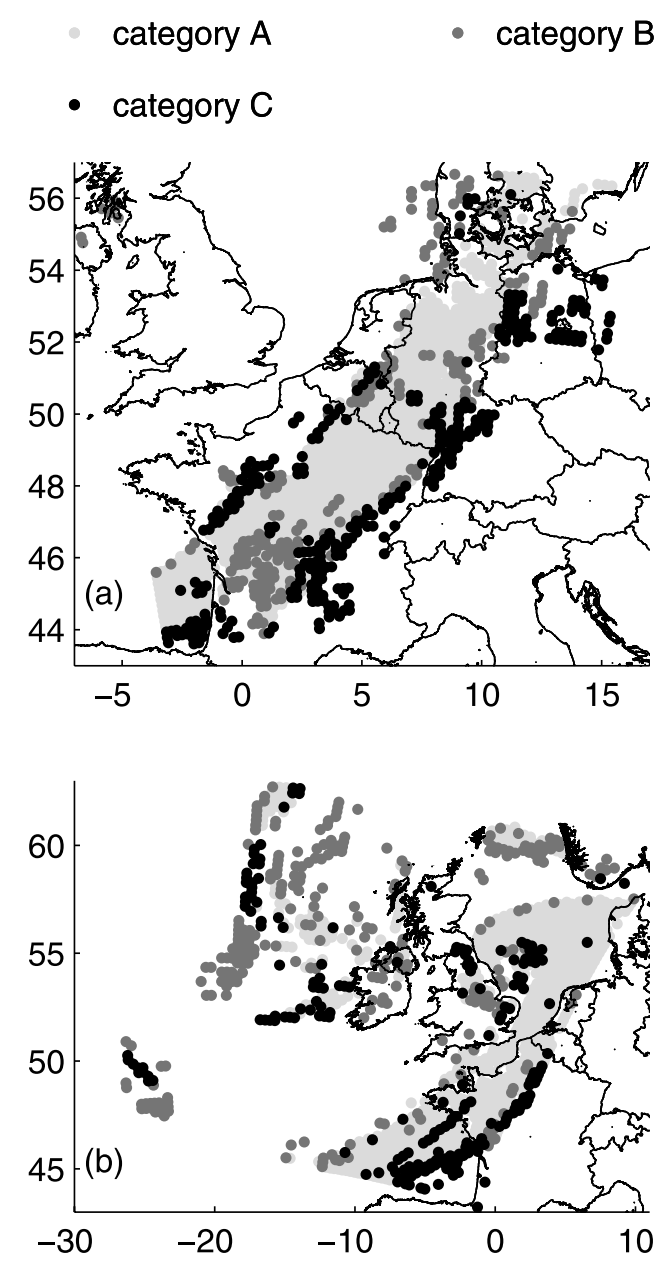

Figure 3. Results of the classification for two scenes using the frequency range F02 (AMSU-AB) for $19^{\circ}$ incidence angle. Categories are the same as in Table 2. 


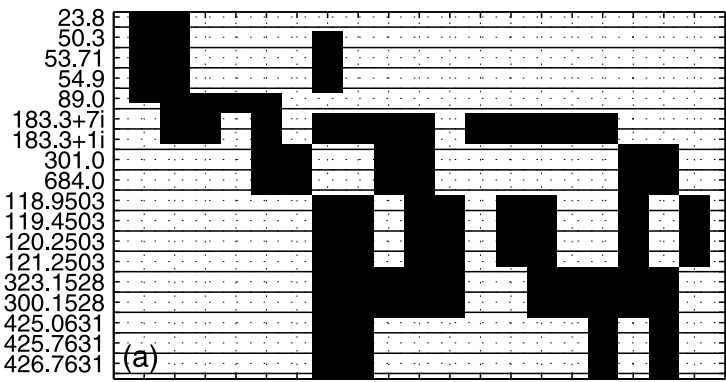
31.4
52.8
54.4 54.4
55.5 150.0 $183.3+3 i$ 220.5
462.5 462.5
875.0 119.1503 119.8503 120.7503
324.6528 318.1528 318.1528
379.6976 426.7631 (a) ,
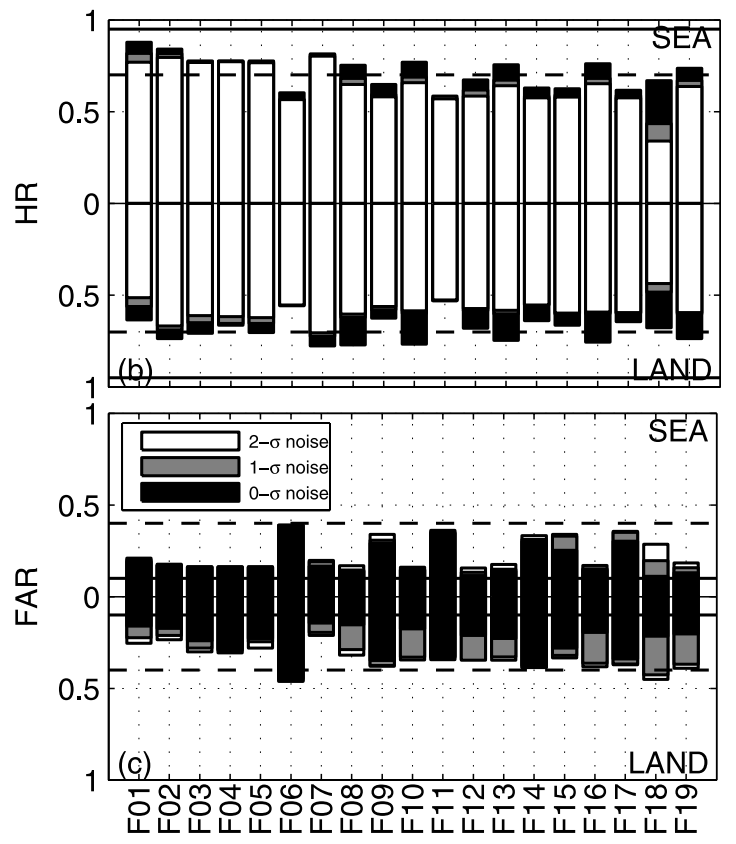

frequency set

Figure 4. Performances of the classification for the 19 frequency sets defined in (a), at $19^{\circ}$ incidence angle as determined from the Hit Rate (HR, (b)) and the False Alarm Rate (FAR, (c)). See text for the definition of HR and FAR. The breakthrough values defined in the EUMETSAT position paper for NWP and NWC are indicated with solid and dashed lines, respectively.

for most combinations without noise added. In the presence of noise, only the F18 frequency combination (only $118 \mathrm{GHz}$ channels) exhibits significant changes in both HR and FAR while for the other frequency sets the variations of HR and FAR are relatively limited. For most frequency sets one can observe a dissymmetry of HR and FAR above sea and land. The classification at AMSU-A frequencies (F01) performs better over sea than over land according to its HR for the three noise configurations. This frequency combination has the highest HR over sea for the noise-free configuration and is slightly less performant than the GOMAS configuration (F07) when the 2-sigma noise configuration is applied: The low frequency window channels provide the sensitivity to the rain emission over the oceanic cold background (related to the low ocean emissivity). Over land, the HR is higher when higher frequencies are used due to their sensitivity to scattering effects: Scattering by the hydrometeors at high frequencies is observed over the high emissivity background. The fre- quency set corresponding to the high frequency window channels alone (F06) exhibits the lowest HR scores of all frequency ranges for all noise configurations as well as the highest FAR, for both sea and land pixels. When profiling capabilities are added (observations in $\mathrm{O}_{2}$ and/or $\mathrm{H}_{2} \mathrm{O}$ lines such as in the combination F09), the performances are improved. The frequency combination planned for geostationary missions (F07) can provide a HR of rain events larger than $70 \%$ with a FAR of the order of $20 \%$, according to the present theoretical work for the three noise levels considered. This is within the breakthrough thresholds requested for nowcasting. Even if the lower frequency channels are suppressed for spatial resolution considerations (F08), the HR remains close to the HR breakthrough threshold and the FAR stays below the FAR breakthrough threshold. Suppressing the $\mathrm{O}_{2}$ channels at $424 \mathrm{GHz}$ does not significantly affect the results, as seen by the comparisons of the F08 and F13 sets, but suppressing the $\mathrm{O}_{2} 118 \mathrm{GHz}$ channels does (compare F08 and F15). All the sets that do not have frequencies below $150 \mathrm{GHz}$ (F06, F09, F11, F14, F15, F17) exhibit poor scores, even poorer at higher noise level, over land and ocean. It appears that the role of the sounding channel in $\mathrm{O}_{2}$ lines (around 50 and/or $118 \mathrm{GHz}$ ) is significant, due to their potential to sound at different altitudes in the atmospheric column. However, it is also due to the fact that these frequencies are rather low compared to the other millimeter and sub-millimeter channels and penetrate deeper into the clouds. Discussions about the respective role of the $\mathrm{H}_{2} \mathrm{O}$ and $\mathrm{O}_{2}$ sounding channels [e.g., Pinori et al., 2006] should make clear that part of the merit of the $\mathrm{O}_{2}$ sounding channels as compared to the $\mathrm{H}_{2} \mathrm{O}$ channels is due to the fact that the $\mathrm{O}_{2}$ lines at 50 and $118 \mathrm{GHz}$ are located at lower frequencies than the $\mathrm{H}_{2} \mathrm{O}$ lower frequency line for sounding $(183 \mathrm{GHz})$, thus providing a deeper penetration within the cloud structure. Note that the $118 \mathrm{GHz}$ channels alone (F18) perform almost within the thresholds in the absence of noise but exhibits the worst performances when realistic noises are considered. Adding the $183 \mathrm{GHz}$ set to the $118 \mathrm{GHz}$ one (F12) does improve the results of the $118 \mathrm{GHz}$ alone. The $118 \mathrm{O}_{2}$ and $325 / 380 \mathrm{H}_{2} \mathrm{O}$ combination (F19) yields acceptable performances, better than the $118 \mathrm{O}_{2} / 183 \mathrm{H}_{2} \mathrm{O}$ combination (F12). Adding the high window frequencies also helps the detection slightly (compare F19 and F16). The performances have been tested for the other incidence angles and the relative changes are insignificant.

[29] Figure 5 presents the initial rain rate distribution as well as the rain rate distributions of pixels misclassified as non-rainy for different frequency sets, for sea and land separately and for the three noise configurations. For both surface types, the high rain rates $(>5 \mathrm{~mm} / \mathrm{h})$ are well detected regardless of the frequency combination and the noise configuration suggesting that the detection of intense rain can easily be achieved even at high frequencies, i.e., with a configuration such as HF-GOMAS (F08). The lower the rain rate, the more difficult the detection of the rain especially for $\mathrm{RR}<0.3 \mathrm{~mm} / \mathrm{h}$ over sea and $\mathrm{RR}<2 \mathrm{~mm} / \mathrm{h}$ over land. Over land, rain is essentially detected through the scattering signatures of the ice phase, and, as a consequence, the low rain rates that are associated with stratiform situations with a limited ice phase or without it cannot be easily detected. 


$$
\begin{array}{ll}
\text { - Initial } & \text { - AMSU-AB } \\
\text { - AMSU-A } & - \text { AMSU-B }
\end{array}
$$
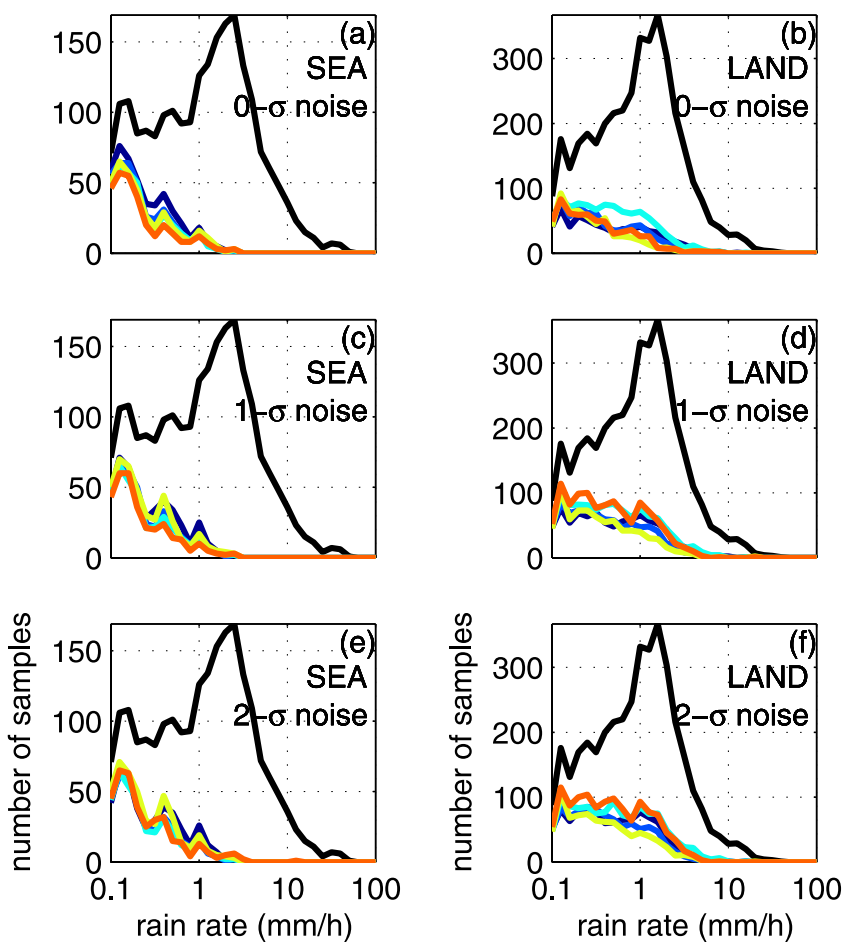

Figure 5. Histograms of the mis-classified rainy pixels for sea (a) and land (b) (i.e., pixels classified non-rainy that were rainy) for different noise level. The black line indicates the initial rain rate for each surface type, and each color line corresponds to a frequency set.

[30] In conclusion, the use of channels at rather low frequencies is necessary to provide a good rain detection over ocean. The addition of frequency channels below $100 \mathrm{GHz}$ improves the results, especially over ocean, but given the spatial resolution problem from geostationary platforms and the rather limited improvement they provide, it might not be recommended. Observations in high frequency window channels only are clearly not enough and sounding channels have to be added. For precipitation detection purposes, the $424 \mathrm{GHz}$ observations are not necessary. A frequency set such as planned for GOMAS should provide precipitation detection within the threshold values, and close to them if the channels in the $\mathrm{O}_{2} 50 \mathrm{GHz}$ lines are suppressed. Frequencies below $150 \mathrm{GHz}$ (such as the $118 \mathrm{GHz}$ sounding channels) will have to be added to an instrument like CIWSIR to detect precipitation with a suitable accuracy.

\section{Retrieval Results}

\subsection{Rain Rate}

[31] RR retrieval is applied to the rainy pixels. The results from both ML and NN approaches over sea are plotted in Figures 6 and 7 for eleven different frequency combinations at $19^{\circ}$ incidence angle for the noise-free configuration. For selected frequency ranges, the initial (from Meso-NH) and retrieved RRs are plotted in terms of the density of initial- retrieved RR pairs per bin of 0.1 (in logarithmic scale of $\mathrm{mm} / \mathrm{h}$ ). Comparisons between the ML and $\mathrm{NN}$ methods clearly show that for all frequency combinations the ML scheme undergoes saturation effects at low and/or high rain rates and exhibits larger dispersion at low rain rates: The $\mathrm{NN}$ inversion makes it possible to account for the non-linear relationships between the rain rate and the brightness temperatures and saturation effects are limited. The NN results (Figure 7) show that the RR retrievals for frequency ranges containing frequencies below $100 \mathrm{GHz}$ (i.e., F01, F02 and F07) present less dispersion. This is also obvious when comparing the results for the geostationary project with the $\mathrm{O}_{2}$ channels around $50 \mathrm{GHz}$ (F07) and in their absence (F08). The $50 \mathrm{GHz}$ frequencies included in the set planned for geostationary application (F07) as well as in AMSU-A and AMSU-AB improve significantly the results of the RR retrieval over sea. Using only window frequencies above $200 \mathrm{GHz}$ (F06) does not appear suitable for retrieving accurate $\mathrm{RR}$ over the entire $\mathrm{RR}$ range but has potential for the detection of significant rain events. The dispersion is usually close to symmetry around the diagonal suggesting the absence of significant biases. Similar results are observed over land (not shown) but with a larger dispersion for low rain rates.

[32] For each RR bin, the errors $e_{r m s}$ and $e_{m}$ as defined in section 2 are documented in Figure 8, along with the standard deviation around the error $e_{m}$ (vertical segments), for the NN inversion over ocean at $19^{\circ}$ incidence angle for the noise-free configuration. The errors usually decrease when RR increases. Note that $e_{r m s}$ and $e_{m}$ can be significantly different, explaining in part the differences in the results obtained from one study to the other when the error definitions are not identical. At AMSU-A (F01), AMSU$\mathrm{AB}$ (F02), or at frequencies selected for geostationary projects (F07), the errors are within 50\% for RR above $0.5 \mathrm{~mm} / \mathrm{h}$, i.e., are well within the threshold values of $100 \%$ requested for NWP application and below the breakthrough values of $50 \%$ (Table 1). Suppressing the $118 \mathrm{GHz} \mathrm{O}_{2}$ channels (F09) degrades the results below $1 \mathrm{~mm} / \mathrm{h}$ but not above. However, all these measurement combinations are clearly not suitable for land surface hydrology applications given the accuracy specified in Table 1. Strong precipitation events (RR $>10 \mathrm{~mm} / \mathrm{h}$ ) can be quantified with errors around $50 \%$ for all frequency configurations. A frequency combination similar to CIWSIR (F09) does not provide the requested accuracy but the addition of the $118 \mathrm{GHz}$ channel does improve the results. A simple instrument combining the $118 \mathrm{GHz} \mathrm{O}_{2}$ and the $325 / 380 \mathrm{GHz} \mathrm{H}_{2} \mathrm{O}$ (F19) sets yields performances close to the specifications for $\mathrm{RR}>1 \mathrm{~mm} / \mathrm{h}$. The other incidence angles have also been examined. Figure 9 shows the results for the F07 frequency set over ocean and land. The results are comparable for all incidence angles.

[33] Figure 10 synthesizes the r.m.s. errors as a function of rain rate for five selected frequency combinations and compares the performances over sea and land (results are presented at $19^{\circ}$ incidence angle). The addition of the IR channel is also examined. Over land, the low frequencies play a much weaker role and suppressing the frequencies below $100 \mathrm{GHz}$ from F07 for instance (i.e., set F08) does not change the results significantly, contrarily to what is observed over ocean especially below $1 \mathrm{~mm} / \mathrm{h}$. Regardless 

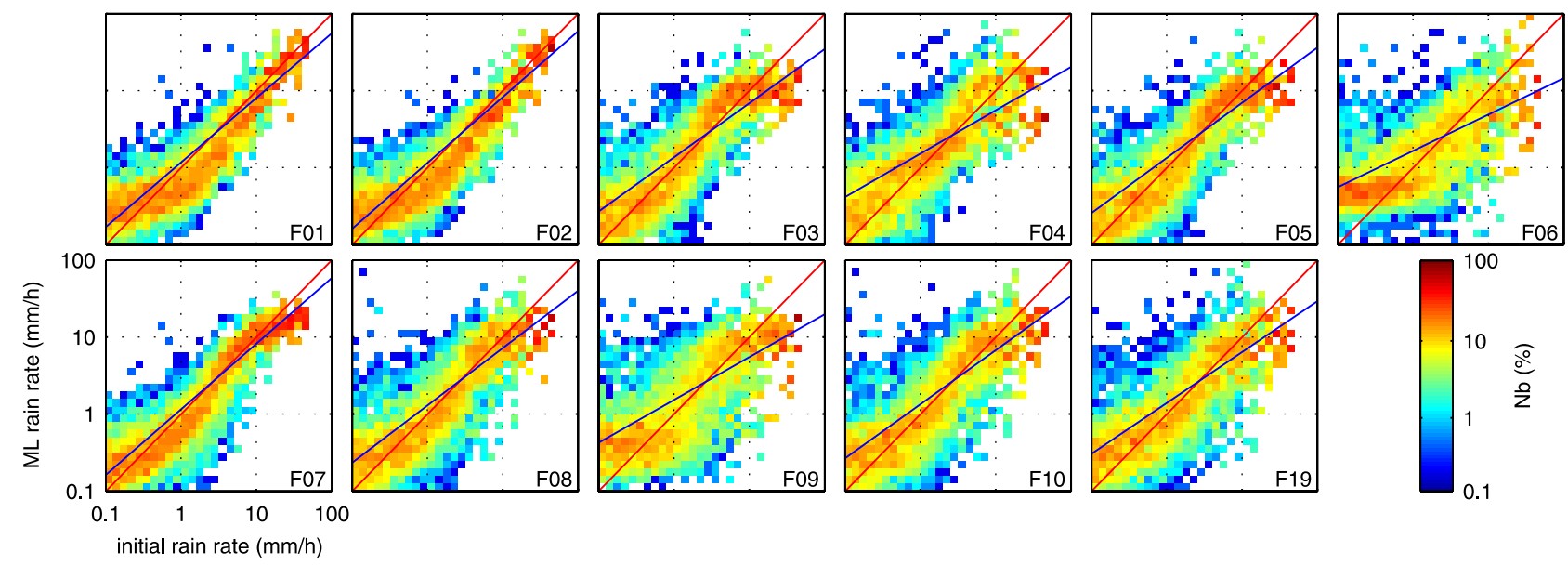

Figure 6. Density of initial-retrieved rain rate pairs per bin of 0.1 . The results are presented over sea at $19^{\circ}$ incidence angle for the multilinear inversion scheme. The density is expressed in $\%$ relative to the total number of initial samples within a given $0.1 \mathrm{bin}$.

of the frequency combination, the retrieval of low rain rate $(<0.5 \mathrm{~mm} / \mathrm{h})$ over land presents errors larger than $100 \%$. Adding the thermal infrared has almost no impact, except for the configurations that originally suffered from large errors. Over land and ocean, the RMS errors with a geostationary type configuration (F07) are below or close to $50 \%$ for rain rates above $1 \mathrm{~mm} / \mathrm{h}$, similar to what can be obtained with AMSU-A or AMSU-AB instruments (F01 and F02). Between 0.5 and $1 \mathrm{~mm} / \mathrm{h}$, it is still true over ocean but not over land where it can reach the $100 \%$ threshold value (Table 1). Below $0.5 \mathrm{~mm} / \mathrm{h}$ and regardless of the surface type, the rain rate retrievals are too much uncertain that they bring no value in a NWP framework.

[34] Figure 11 presents the RMS for two frequency sets (GOMAS and HF-GOMAS) over ocean and land separately and for the three noise configurations. Introducing noise in the treatment induces small variations in the retrieval performances except for the F08 frequency set (HFGOMAS) for low rain rates over ocean. Above $1 \mathrm{~mm} / \mathrm{h}$ the impact of the noise is very limited: The rain and related clouds above induce changes in the brightness temperatures that are well above the specified instrumental noise levels. Similar sensitivity to the noise has been obtained by Mech et al. [2007].

\subsection{Integrated Ice}

[35] So far we have concentrated on the retrieval of the rain rate. Identically, the other hydrometeor quantities can be retrieved with the same method and we systematically retrieved the integrated quantities for all the hydrometeor species (cloud water, rain, ice, snow, and graupel). Because the methodology was first developed to investigate RR retrieval and starts by a classification of the rainy pixels, the other hydrometeor species are only retrieved for precipitating cells in this study. Following the same method, we could derive algorithms for all cloudy pixels based on a preliminary classification of clear and cloudy scenes but this is beyond the scope of this study. The retrieval of ice and cloud parameters is not our main focus here: The potential of the millimeter and sub-millimeter ranges for ice characterization has already been explored by Evans et al. [2002] or by Buehler et al. [2005, 2007]. We briefly show some
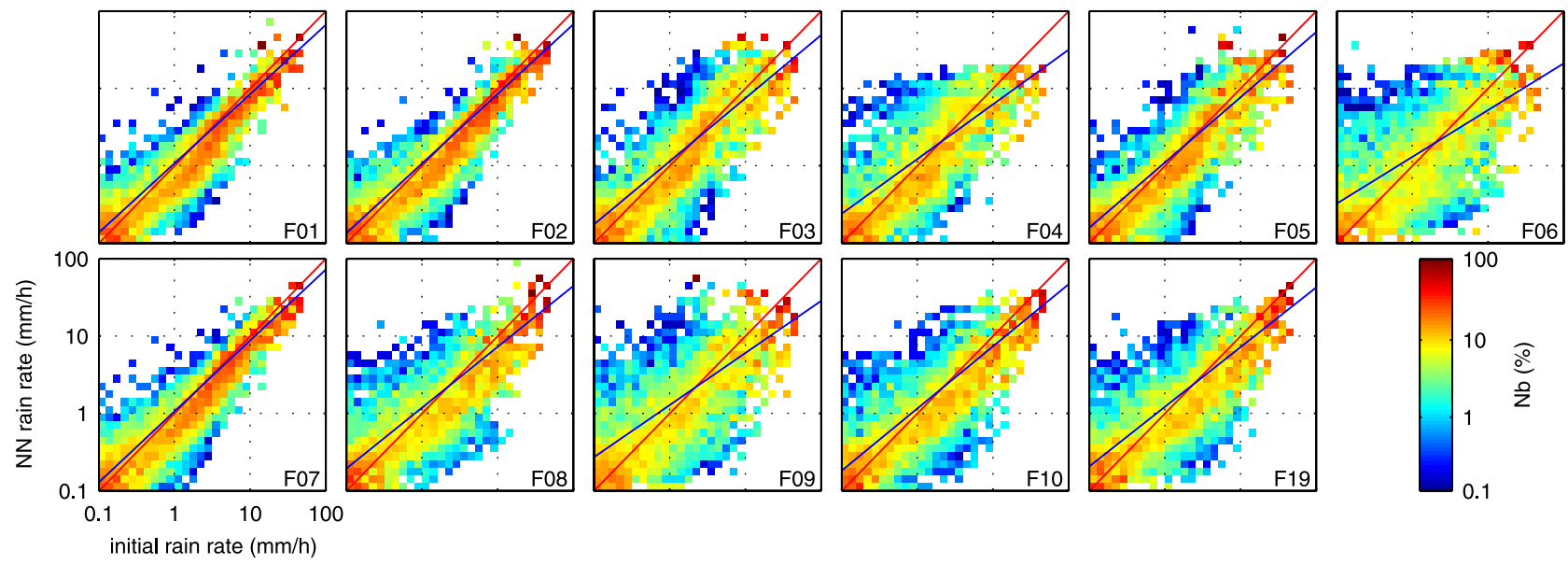

Figure 7. Same as in Figure 6 except the results are for the neural network inversion scheme. 

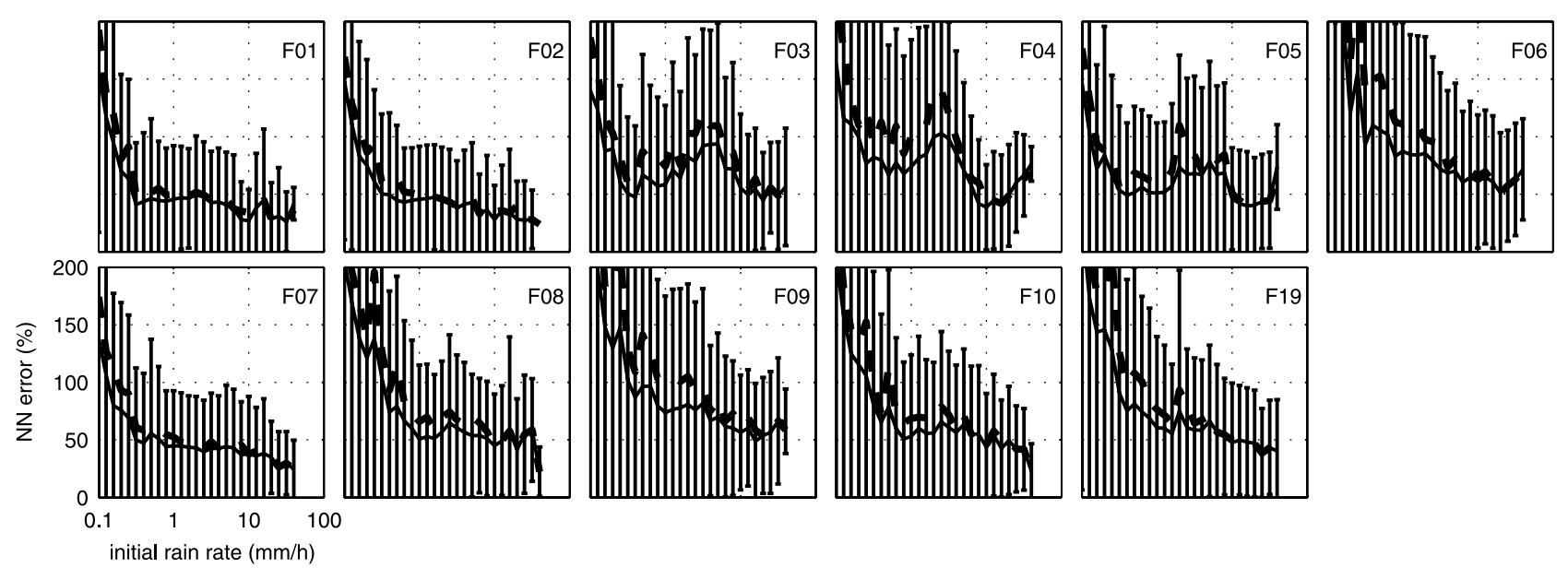

Figure 8. Mean absolute relative error $\mathrm{e}_{\mathrm{m}}$ (solid lines) \pm the standard deviations (vertical segment) and the RMS errors $\mathrm{e}_{\mathrm{rms}}$ (dashed line) computed per 0.1 bin for pixels over ocean at $19^{\circ}$ incidence angle with the neural network (NN) method for different frequency sets (see the text for the definition of the errors).

results about the total ice content obtained with the set of frequencies considered here for geostationary applications.

[36] Similar to Figure 7 (case F07), Figure 12a presents the results for the integrated total ice retrieval (ice + snow + graupel), for the $\mathrm{NN}$ method at $19^{\circ}$ incidence angle over ocean in the absence of noise. The densities are plotted for each bin of $0.4 \mathrm{~kg} / \mathrm{m}^{2}$. The retrievals are distributed very close to the diagonal. The average error for total-ice retrieval is below $40 \%$ and for most of the bins close or below 20\% (Figure 12b). This is within the threshold of $50 \%$ specified by the user requirements for this quantity and close to the $20 \%$ breakthrough value [Rizzi et al., 2006]. The performances we obtain are similar to what is expected from CIWSIR that also contains sounding channels around the $\mathrm{H}_{2} \mathrm{O}$ lines at 183,325 , and $448 \mathrm{GHz}$ along with window channels at 243, 664, and $874 \mathrm{GHz}$ [Buehler et al., 2007].

\subsection{Profiling Capability}

[37] In addition to the estimation of the integrated hydrometeor quantities, the various frequency combinations are tested for the retrieval of the hydrometeor profiles. We concentrate here on the rain profiling capability.

[38] Figure 13 presents the results obtained with the NN inversion for the rain profile over ocean, for a $19^{\circ}$ incidence angle in the absence of noise. The parameter plotted here corresponds to the mixing ratio of rain $(\mathrm{kg} / \mathrm{kg})$, that is the ratio of rainwater mass over dry air mass directly provided

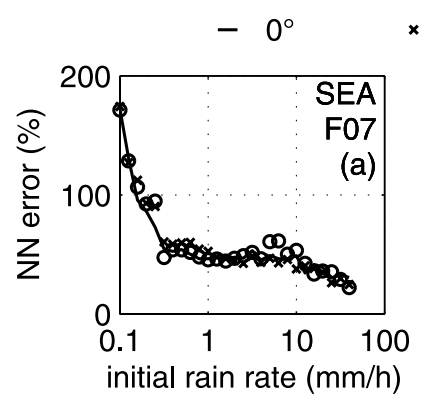

$$
19
$$

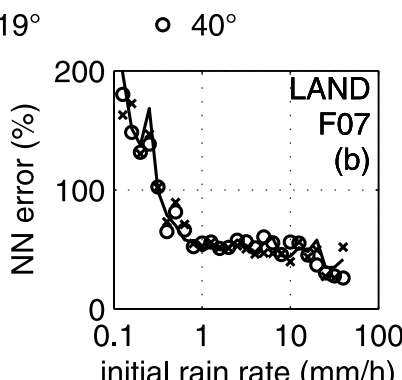

Figure 9. Variations of the RMS error $\mathrm{e}_{\mathrm{rms}}$ as a function of the incidence angle for the frequency set F07 with the neural network (NN) method over ocean (a) and land (b). by the cloud model. The RMS error ( $e_{r m s}$ section II) is computed per bin of mixing ratio of rain and per level. The grey scale follows the error thresholds defined by the user requirements (Table 1). As already observed for the rain rate, the errors decrease with increasing rain contents. Frequency sets having low frequencies as well as sounding frequencies (F02 and F07) provide better retrievals for low rain contents. For a given rain content, the accuracy is usually better at higher altitude than close to the surface, as expected due to the increased attenuation when sounding closer to the surface and due to the surface radiation contribution. Except for the very low rain content, the RMS error is below the breakthrough threshold of $50 \%$ and for the sets that include low frequencies (F02 and F07) the RMS error is larger than $100 \%$ only for the very low rain contents. Over land, the results are slightly worse, especially at low altitudes. This profiling capability is partly due to the correlation between the integrated contents and the vertical distribution. These vertical distribution shapes are captured by the PCA pre-processing step that facilitates the profile retrievals.
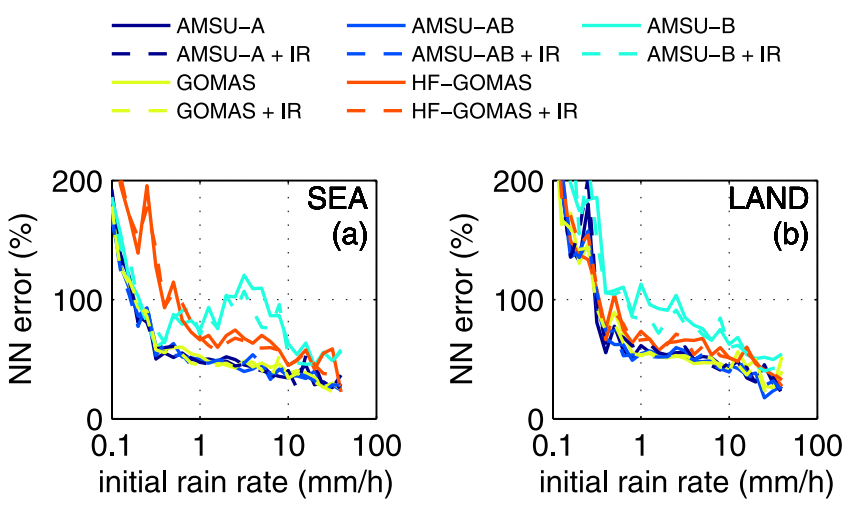

Figure 10. Average RMS error $e_{r m s}$ per rain rate bin for different frequency combinations over sea (a) and land (b) without (solid lines) and with (dashed lines) IR observations. The incidence angle is $19^{\circ}$ and the neural network (NN) retrieval is used. 


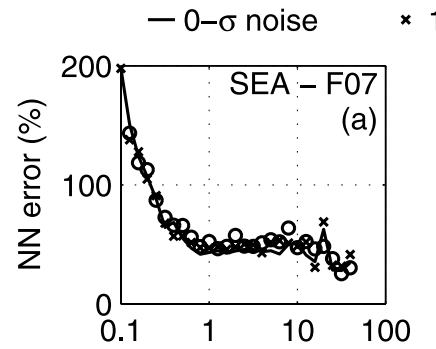

$$
\frac{1}{210}
$$

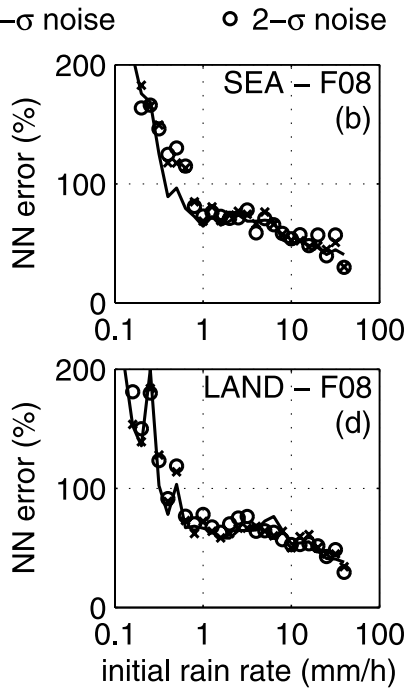

Figure 11. Variations of the RMS error $\mathrm{e}_{\mathrm{rms}}$ for $\mathrm{F} 07$ and F08 frequency sets at different noise configurations with the neural network $(\mathrm{NN})$ method over ocean and land.

\section{Testing the Method at AMSU-B Frequencies Against Radar Observations}

[39] In order to evaluate the rain rate inversion method, it is applied to close-to-millimeter wavelength observations (AMSU-B) and the results are compared to radar measurements. Coincident AMSU-B and radar observations have been collected during the BALTic sea EXperiment (BALTEX) campaign and specific measurements for this study have been performed with the CAMRa radar.

[40] The two-step method is applied to the AMSU-B observations $(89,150,183 \pm 1,183 \pm 3,183 \pm 7 \mathrm{GHz})$. First, the rain classification selects the rainy pixels then the inversion algorithm is applied to these pixels. The AMSU instrument is a cross-track scanner and for each beam position the algorithm corresponding to the incident angle is adopted. In the previous analysis, it was shown that the frequency combination corresponding to AMSU-B is not optimum and shows poorer performances than what is
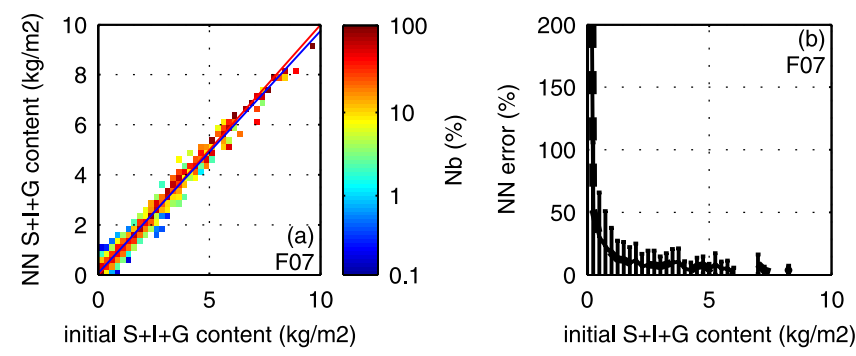

Figure 12. (a) Density of initial-retrieved total (Ice + Snow + Graupel) ice content pairs per bin of 0.1 normalized to its maximum value for sea pixels with the NN method; (b) RMS error $\mathrm{e}_{\mathrm{rms}}$ (solid line) \pm standard deviation (vertical segment) of total (Snow + Ice + Graupel) ice retrieval for sea pixels and with neural network (NN) method per bin of 0.1 .

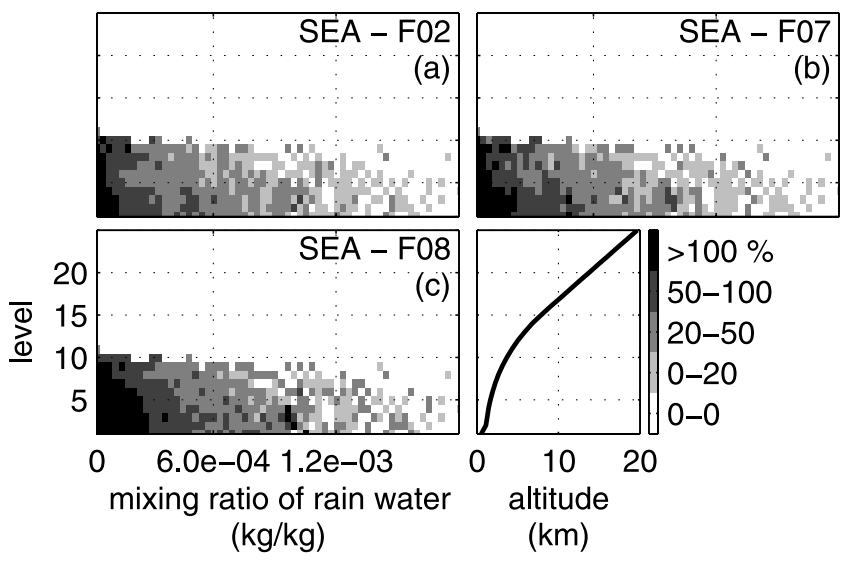

Figure 13. Example of vertical profiles of rain rate over ocean for different frequency ranges at $19^{\circ}$ incidence angle with the neural network (NN) method. The RMS error is computed per bin of rain and per level. The grey scale follows the error thresholds defined by the user requirements (Table 1).

expected for the recommended channel sets. As a consequence, it is likely to underestimate the performances as compared to the recommended frequency combination. The AMSU-AB combination has not been tested due to the poorer spatial resolution at AMSU-A frequencies that would seriously hamper the comparison with radar scenes of limited extent (especially for the comparison with the CAMRa radar).

\subsection{Comparisons With the BALTEX Radars}

[41] During BALTEX, the Swedish Meteorological and Hydrological Institute (SMHI) was responsible for the collection and distribution of the hydrological and radar data sets. The BALTEX radar network consists of 29 radars (most of them in C-band) located in Northern Europe [Michelson and Koistinen, 2000]. The radar products are adjusted using rain gauge measurements, at 0600 and 1800 UTC each day. The radar reflectivity factors are converted to rain rate using a Z-R relation that depends on the season.

[42] In addition to our own algorithm, for comparison purposes two rain detection algorithms developed for AMSU-B measurement are applied to the satellite observations. Grody et al. [1999] provide a rain flag for each AMSU-B pixel. Bennartz et al. [2002] characterize each AMSU pixel with a 4-class rain classification (CL1 : RR < 0.1, CL2 : $0.1<\mathrm{RR}<0.5$, CL3 : $0.5<\mathrm{RR}<5$, CL4 : $5<$ $\mathrm{RR}$ in $\mathrm{mm} / \mathrm{h}$ ) that was derived from the analysis of coincident radar and AMSU observations during BALTEX (as a consequence, the performances of this algorithm are best for the comparisons with the BALTEX observations). Figure 14 presents an example of retrieval maps for one case recorded during the BALTEX experiment (12 July 2000, at 15UTC). Most of AMSU-B brightness temperatures exhibit a decrease in amplitude where the radar observations indicate the presence of rain (Figures 14a14d) showing the consistency of the space-borne and ground-based measurements. The classification from Bennartz et al. [2002] (Figure 14e) identifies several regions with significant rain, located where the brightness temperatures 


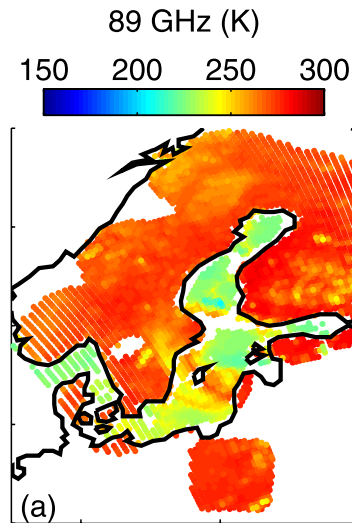

(a)

- CL1

Bennartz class.

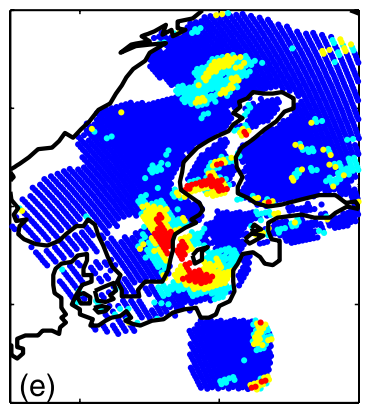

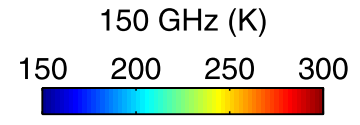

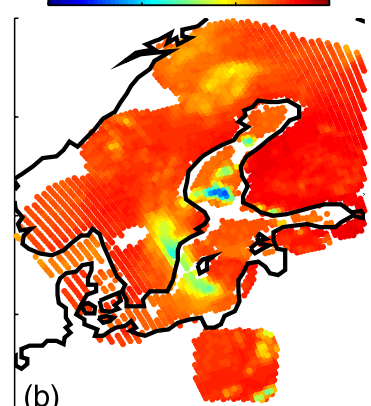

(b)

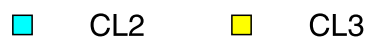

Grody class.

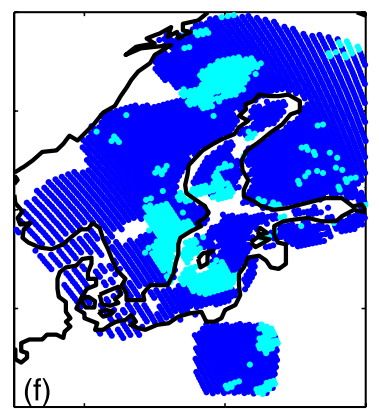

$183+/-7 \mathrm{GHz}(\mathrm{K})$
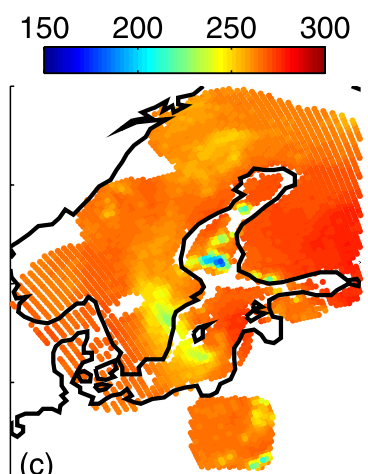

CL4

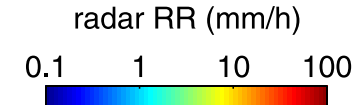

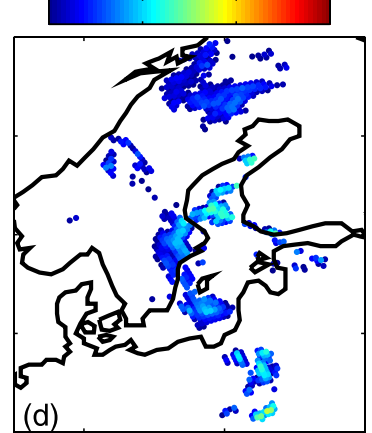

retrieved $\mathrm{RR}(\mathrm{mm} / \mathrm{h})$
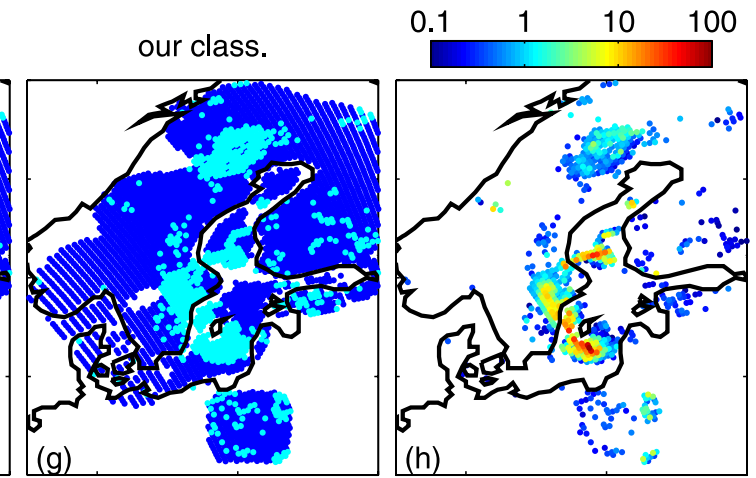

Figure 14. A case during BALTEX (12 July 2000, 15 UTC). Panels (a) to (c): Observed AMSU-B brightness temperatures; (d): Coincident radar rain rate $(\mathrm{mm} / \mathrm{h})$; (e): Bennartz et al. [2002] rain classification composed of 4 classes; (f): Grody et al. [1999] rain detection; (g): Rain detection based on our methodology; (h): Rain rate (RR) retrieval from our method. RR ( $\mathrm{mm} / \mathrm{h})$ is plotted in logarithmic scale.

are significantly depressed. The Grody et al. [1999] classification (Figure 14f) delineates rainy regions similar to the ones identified by Bennartz et al. [2002]. The rain classification developed in the present study provides quite similar locations for rainy regions (Figure $14 \mathrm{~g}$ ), both over land and sea. The spatial structures of the three satellite-based rain detection algorithms are very similar and, compared to the radar rain detection, they show the same differences, with a region of rain missed in northern Norway and slightly displaced structures in the Gulf of Bothnia.

[43] Our rain rate estimates are presented on Figure 14h: Although a specific algorithm is developed for each incidence angle range and surface type, there is no discontinuity in the rain rate field. Compared to the radar measurements, the RR derived from AMSU-B observations are clearly overestimated. This is also the case for the Bennartz et al. [2002] algorithm although it has been specifically developed during this measurement campaign. This can be due to (1) an underestimation of the radar rain rate for this particular situation (2) the inability of the AMSU-B frequencies to quantify this type of rain event. The similar results obtained by Bennartz et al. [2002] and our algorithms tend to show that our retrieval method cannot be directly incriminated.

[44] A total of 120 overpasses covering totally or partially the BALTEX domain during the entire year 2000 were investigated to perform a statistically representative study. Rain rates derived from radar observations and convoluted according to the AMSU-B beam patterns ranged from 0.1 to $14 \mathrm{~mm} / \mathrm{h}$. In that database, about $12 \%$ of the rainy pixels exhibited a rain rate exceeding $1 \mathrm{~mm} / \mathrm{h}$. AMSU overpasses occurred roughly at 06 and 18 UTC and radar observations were collected in a temporal range of $10 \mathrm{~min}$. HR and FAR were calculated for three rain detection methods separating the results by surface types and by 6-month period. In the present data set, Bennartz et al.'s [2002] rain detection tool performs better both over sea and land compared to the two other tools which is expected considering the fact that this algorithm was built from the BALTEX observations. All detection tools performed better during the warm season (May to October) than during the cold season: With our algorithm, the mean HR over sea is 0.69 during the summer and 0.56 during the winter. During summer, the rain is more likely to be convective and as a consequence easier to detect with high frequencies.

\subsection{Comparisons With the CAMRa Radar}

[45] The Chilbolton Facility for Atmospheric and Radio Research established a set of ground validation test cases, by performing radar scans during AMSU-B overpasses for both stratiform and convective cases. The Chilbolton Advanced Meteorological Radar (CAMRa) [Goddard et al., 1994] is unique in incorporating a fully steerable $25 \mathrm{~m}$ antenna. This provides an extremely narrow $\left(0.25^{\circ}\right)$ beam, giving a high spatial resolution $(0.4 \mathrm{~km}$ at $100 \mathrm{~km}$ range). Rain rates were determined using reflectivity $(Z)$ and differ- 


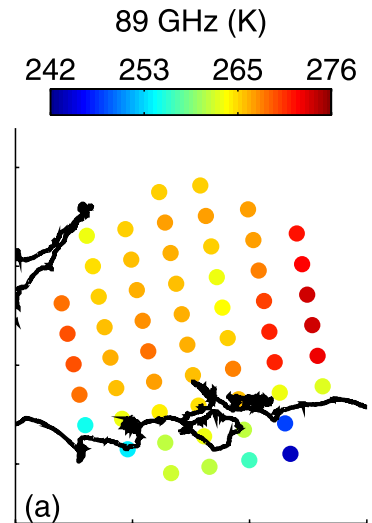

(a)

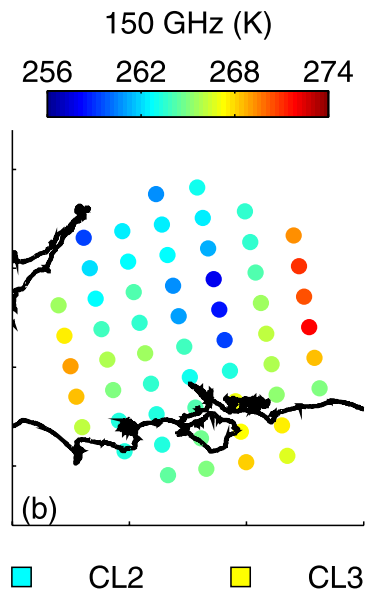

Grody class.

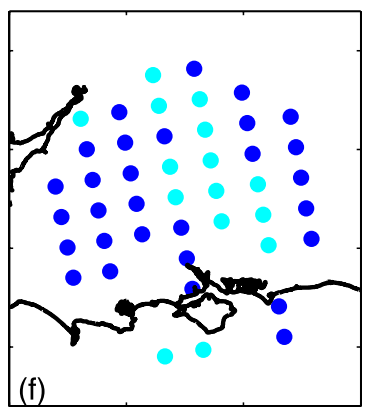

$183+/-7 \mathrm{GHz}(\mathrm{K})$
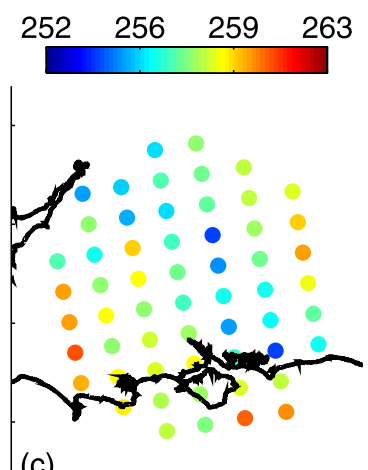

(c)

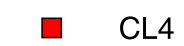

our class

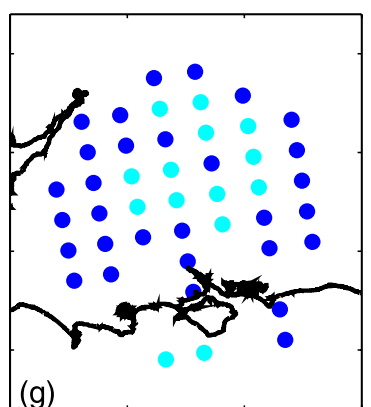

radar $\mathrm{RR}(\mathrm{mm} / \mathrm{h})$
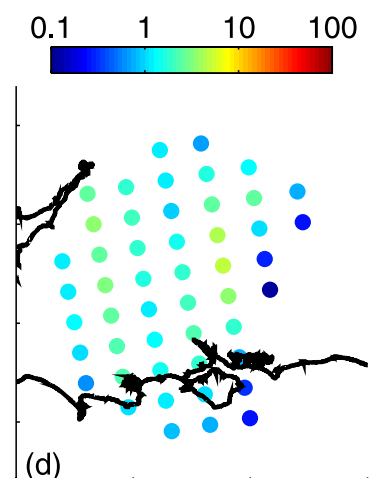

retrieved $R R(\mathrm{~mm} / \mathrm{h})$
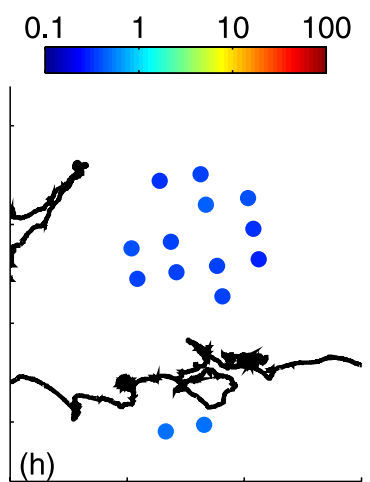

Figure 15. Same as Figure 14 but for a comparison with the Chilbolton radar estimates on 21 April 2004, 14:10 UTC.

ential reflectivity (ZDR) data via the formula of Illingworth and Blackman [2002] for ZDR $>0.5 \mathrm{~dB}$ and via a standard power law Z-R relation otherwise. Bright-band corrections were applied using the method proposed by Smyth and Illingworth [1998]. To enable comparison with AMSU-B retrievals the radar-derived data were transformed using a Cressman filter to a fine-scale coordinate grid interpolated from the AMSU-B swath, and then convolved with a Gaussian approximation of the AMSU-B antenna pattern to establish a single ground-truth value for each satellite footprint.

[46] Figure 15 presents a case on 21 April 2004, at 14:10 UTC. The NOAA-16 overpass was at approximately 14:07:30 and the radar scan took place between 14:08:13 and 14:13:59, suggesting a relatively good simultaneity of both ground-based and space-borne observations. Compared to the previous case (Figure 14), the AMSU-B brightness temperatures (Figures 15a, 15b, and 15c) are very homogeneous and do not show significant effects of scattering by the cloud structure, although the rain rate measured by the radar reaches $5.2 \mathrm{~mm} / \mathrm{h}$ locally (Figure $15 \mathrm{~d}$ ). The rain detection methods (Figures 15e, 15f, and $15 \mathrm{~g}$ ) all miss large parts of the rain area and they all have very similar structures (coastal pixels have not been treated). As a consequence, over land the FAR is very good but the HR is rather low for all methods. The estimated rain rates by our method (Figure 15h) are very close to the radar estimates in the region where rain has been correctly detected.

[47] A total number of 1727 AMSU beams colocated within the CAMRa domain (60\% over land, $12 \%$ over sea,
$28 \%$ on coastlines) from 45 different AMSU overpasses was analyzed to determine the performances of the rain detection tool. Time intervals between the radar observations and the satellite measurements ranged from a few seconds up to $30 \mathrm{~min}$ while rain rate (convoluted according to AMSU beam patterns) varies up to $7 \mathrm{~mm} / \mathrm{h}$. Over sea, our rain detection tool detects correctly the rain pixels with an HR above 0.7 (NWC breakthrough threshold, Table 1) and the rain detection tool from Bennartz et al. [2002] performs even better. The FAR for pixels over sea is almost of the same order of magnitude for the three rain detection tools and remains below the NWC breakthrough threshold of 0.4 . Over land the rain detection performances exhibit HR below the NWC breakthrough threshold whatever the rain detection tool while the FAR is well below the NWC breakthrough threshold. Study of the HR as a function of the rain rate reveals that over sea (land), HR reaches $0.9(0.5), 1$ $(0.5)$, and $0.7(0.5)$ for a rain rate above $1 \mathrm{~mm} / \mathrm{h}$ suggesting that highly precipitating events can be well detected over sea while over land only $50 \%$ of the rainy pixels are detected regardless the rain detection tool. In terms of RR retrieval performance, the RMS varies similarly to the one obtained theoretically: The higher the rain rate, the lower the RMS with a value around $90 \%$ for rain rate ranging from 1 to $6 \mathrm{~mm} / \mathrm{h}$.

[48] These comparisons with the BALTEX and CAMRa radars show that our method, only based on simulations, has performances similar to the other methodologies developed directly from comparisons between radar and satellite observations [Bennartz et al., 2002]. This confirms the 
validity of the method for this frequency range and gives confidence in its extrapolation to higher frequencies. As the AMSU-B frequency combination (F03) shows poorer performances than the recommended channel sets such as F08 (see Figures 4 and 8), both in terms of detection and quantification of the rain rate, these comparison results are clearly an underestimation of what could be obtained with optimized frequency sets.

\section{Conclusion}

[49] The importance of millimeter and sub-millimeter wavelength observations for cloud and precipitation characterization from geosynchronous orbits has been recognized for nowcasting and short range forecasting. The potential of this wavelength range for precipitation retrieval is analyzed in this paper in order to prepare future geostationary missions. The study is based on simulated observations that correspond to five real meteorological situations over Europe. Outputs from the Meso-NH cloud model are coupled to the ATM radiative transfer code and a large range of frequency sets is simulated and tested. For each frequency combination, both rain detection and the rain rate quantification are evaluated and compared to the user requirements recently specified by EUMETSAT. The impact of adding the IR information is also systematically evaluated. The results shown here are very promising.

[50] The theoretical results are evaluated at close-tomillimeter wavelengths, using collocated AMSU-B and radar observations in the Baltic region (BALTEX radars) and over the south of England (the CAMRa radar). As expected, the comparison results are not as good as the theoretical ones but are consistent with them. As the recommended frequency sets for a geostationary mission have better theoretical performances than the AMSU-B channel combination, the radar comparison results with AMSU-B show the lower limit of what can be obtained.

[51] The frequency channels below $100 \mathrm{GHz}$ improve the results for rain rates below $1 \mathrm{~mm} / \mathrm{h}$ over ocean. Over land the role of these frequencies is less important, as expected. For a given antenna size, sounding in the $50 \mathrm{GHz} \mathrm{O}_{2}$ line provides less than half the spatial resolution obtained at $118 \mathrm{GHz}$. For high rain rates such as observed during severe weather events, high frequency observations alone (i.e., no channels below $100 \mathrm{GHz}$ ) can provide result accuracies that are close to the user requirements. With a frequency set similar to GOMAS, the performances are within the breakthrough values specified by Rizzi et al. [2006] for the rain detection for NWC applications and for the rain rate for both NWC and NWP applications, except for the rates below $1 \mathrm{~mm} / \mathrm{h}$. The impact of the $424 \mathrm{GHz}$ channels is only marginal for rain retrieval. The role of the $\mathrm{O}_{2}$ sounding channels around 50 and/or at $118 \mathrm{GHz}$ appears important for rain analysis, whereas sounding in the $\mathrm{H}_{2} \mathrm{O}$ lines does not add much information. However, we cannot conclude that the better ability of the $\mathrm{O}_{2}$ lines compared to the $\mathrm{H}_{2} \mathrm{O}$ lines is only due to the nature of the lines and not to their higher penetration into the cloud structure related to the lower opacities at lower frequencies. A key aspect of the rain detection and quantification from a geostationary orbit lies in the spatial resolution of the measurement. In this analysis, it is assumed that the rain cell fills all fields of view for a given frequency set. This is a limitation that will have to be accounted for but that will be lessened if low frequency channels such as the $\mathrm{O}_{2} 50 \mathrm{GHz}$ are avoided. For the detection and quantification of significant rain events (rain rate above $1 \mathrm{~mm} / \mathrm{h}$ ), the combination of sounding channels in the $\mathrm{O}_{2}$ line at $118 \mathrm{GHz}$ and in the $\mathrm{H}_{2} \mathrm{O}$ lines at 325 and $380 \mathrm{GHz}$ should provide results close to the specifications; a mission with frequencies similar to CIWSIR with the addition of the $118 \mathrm{GHz} \mathrm{O}_{2}$ channels would also have similar performances. Addition of IR observations does not improve the results, except for frequency combinations that initially showed very poor performances. Realistic instrumental noise levels have been tested, and the retrieval performances are rather stable.

[52] In the meteorological community over the last decade, the purposes of the geostationary missions at microwave to sub-millimeter wavelengths focused first on water vapor and temperature profile retrievals to shift more recently toward nowcasting of precipitation and extreme weather events. The objectives of these missions have to be clearly stated and defined in order to optimize the instrument specifications and design a realistic mission that will fully benefit from the high temporal sampling rate provided by the geostationary orbit.

[53] Acknowledgments. This study was supported by ESA under contract 18054/04/NL/FF. Partial support was also provided by EUMETSAT under contract EUM/CO/04/1311/KJG and by CNES under TOSCA contract. We are especially grateful to Ulf Klein (ESA) and Chung-Chi Lin (ESA) who critically reviewed the successive steps of the present work and gave insightful comments. We thank D. Michelson (SMHI) who kindly provided the BALTEX radar data. We also thank Suzane Crewell and Mario Mech for discussions. We are grateful to the three reviewers for their careful reading of the manuscript and constructive comments. Computer resources for Meso-NH simulations were allocated by IDRIS. AMSU data come from the NOAA Satellite Active Archive.

\section{References}

Bauer, P., and A. Mugnai (2003), Precipitation profile retrievals using temperature-sounding microwave observations, J. Geophys. Res., 108(D23), 4730, doi:10.1029/2003JD003572.

Bennartz, R., A. Thoss, A. Dybbroe, and D. B. Michelson (2002), Precipitation analysis using the Advanced Microwave Sounding Unit in support of nowcasting applications, Meteorol. Appl., 9, 177-189.

Bizzari, B., A. Gasiewski, and D. Staelin (2002), Frequent rain observation from geostationary stallite by millimeter submillimeter-wave sounding, Proceedings of the 1st IPWG workshop, Madrid, 23-27 September.

Bizzari, B., et al. (2005), GOMAS - Geostationary Observatory for Microwave Atmospheric Sounding, submitted to ESA in response to the call for ideas for the Next Earth Explorer Core Missions.

Buehler, S., et al. (2005), Cloud Ice Water Submillimeter Imaging Radiometer (CIWSIR), Document in response to the ESA Call For Ideas for the Next Earth Explorer Core Missions.

Buehler, S., et al. (2007), Establishment of mission and instrument requirements to observe cirrus clouds at submillimeter wavelengths, Final report, ESA study.

Chaboureau, J.-P., J.-P. Cammas, P. Mascart, J.-P. Pinty, C. Claud, R. Roca, and J.-J. Morcrette (2000), Evaluation of a cloud system life-cycle simulated by the Méso-NH model during FASTEX using METEOSAT radiances and TOVS-3I cloud retrievals, Q. J. R. Meteorol. Soc., 126(566), 1735-1750.

Chaboureau, J.-P., J.-P. Cammas, P. Mascart, J.-P. Pinty, and J.-P. Lafore (2002), Mesoscale model cloud scheme assessment using satellite observations, J. Geophys. Res., 107(D17), 4301, doi:10.1029/2001JD000714. Chaboureau, J.-P., N. Sohne, J.-P. Pinty, I. Meirold-Mautner, E. Defer, C. Prigent, J. Pardo, M. Mech, and S. Crewell (2008), A midlatitude precipitating cloud database validated with satellite observations, J. Appl. Meteorol. Clim., in press.

Chen, F. W., and D. H. Staelin (2003), AIRS/AMSU/HSB precipitation estimate, IEEE Trans. Geosci. Remote Sens., 41(2), 410-417. 
Duda, R. O., and P. E. Hart (1973), Pattern classification and scene analysis, J. Wiley Interscience.

Evans, K. F., and G. L. Stephens (1995), Microwave radiative transfer through clouds composed of realistically shaped ice crystals. Part I: Single scattering properties, J. Atmos. Sci., 52, 2041-2057.

Evans, K. F., S. J. Walter, A. J. Heymsfield, and G. M. McFarquhar (2002), The submillimeter-wave cloud ice radiometer: Simulations of retrieval algorithm performance, J. Geophys. Res., 107(D3), 4028, doi:10.1029/ 2001JD000709.

Evans, K. F., J. R. Wang, P. E. Racette, G. Heymsfield, and L. Li (2005), Ice cloud retrievals and analysis with the compact scanning submillimeter imaging radiometer and the cloud radar system during CRYSTAL-FACE, J. Appl. Meteorol., 44, 839-859.

Goddard, J. W. F., J. D. Eastment, and M. Thurai (1994), The Chilbolton Advanced Meteorological Radar: A tool for multidisciplinary atmospheric research, Electron. Commun. Eng., 6, 77-86.

Golding, B. W., S. Senesi, K. Browning, B. Bizzarri, W. Benesch, D. Rosenfeld, V. Levizzani, H. Roesli, U. Platt, T. E. Nordeng, J. T. Carmona, P. Ambrosetti, P. Pagano, and M. Kurz (2001), EUMETSAT position paper on observation requirements for nowcasting and very short range forecasting in 2015-2025, EUM/C/49/01/DOC/16, Nov.

Guillou, C., S. J. English, and C. Prigent (1996), Passive microwave airborne measurements of the sea surface response at 89 and $157 \mathrm{GHz}$, J. Geophys. Res., 101, 3775-3788.

Grody, N. C., F. Weng, and R. R. Ferraro (1999), Application of AMSU for obtaining hydrological parameters, microwave radiometry and remote sensing of the Earth's surface and atmosphere, VNU Science Press, Brill Academic Publishers, Inc., pp. 339-351.

Illingworth, A. J., and T. M. Blackman (2002), The need to represent raindrop size spectra as normalized gamma distributions for the interpretation of polarization radar observations, J. Appl. Meteorol., 41, 1578-1583.

Klein, M., and A. J. Gasiewski (2000), Nadir sensitivity of passive millimeter and submillimeter wave channels to clear air temperature and water vapor variations, J. Geophys. Res., 105, 17,481-17,511.

Kummerow, C., Y. Hong, W. S. Olson, S. Yang, R. F. Adler, J. McCollum, R. Ferraro, G. Petty, D.-B. Shin, and T. T. Wilheit (2001), The evolution of the Goddard Profiling Algorithm (GPROF) for rainfall estimation from passive microwave sensors, J. Appl. Meteorol., 40, 1801-1820.

Lafore, J.-P., et al. (1998), The Meso-NH atmospheric simulation system. Part I: Adiabatic formulation and control simulations, Ann. Geophys., 16, 90- 109 .

Lainbrigtsen, B., W. Wilson, A. Tanner, T. Gaier, C. Ruf, and J. Piepmeier (2004), GeoSTAR - A microwave sounder for geostationary satellites, Proc. IGARSS'04, 2, 777-780.

Mech, M., S. Crewell, I. Meirold-Mautner, C. Prigent, and J.-P. Chaboureau (2007), Information content of millimeter observations for hydrometeor properties in mid-latitudes, IEEE Trans. Geosci. Remote Sens., 45, 2287 2299.

Meirold-Mautner, I., C. Prigent, E. Defer, J. R. Pardo, J.-P. Chaboureau, J.-P. Pinty, M. Mech, and S. Crewell (2007), Radiative transfer simulations using mesoscale cloud model outputs: Comparisons with passive microwave and infrared satellite observations for midlatitudes, J. Atmos. Sci., 64 $1550-1568$

Michelson, D. B., and J. Koistinen (2000), Gauge-radar network adjustment for the Baltic Sea experiment, Phys. Chem. Earth, 25, 915-920.

Mishchenko, M. I., J. Hovenier, and L. Travis (2000), Light scattering by non-spherical particles, Elsevier, New York.

Mugnai, A. (2003), EGPM - The proposed European contribution to the global precipitation measurement (GPM) mission, Geophys. Res. Abstr. $5,12,550$.

Olson, W. S., C. D. Kummerow, S. Yang, G. W. Petty, W.-K. Tao, T. L. Bell, S. A. Braun, Y. Wang, S. E. Lang, D. E. Johnson, and C. Chiu (2006), Precipitation and latent heating distributions from satellite passive microwave radiometry. Part I: Improved method and uncertainties, J. Appl. Meteorol. Climatol., 45, 702-720, doi:10.1175/JAM2369.1.

Pardo, J. R., J. Cernicharo, and E. Serabyn (2001), Atmospheric Transmission at Microwaves (ATM): An improved model for $\mathrm{mm} / \mathrm{submm}$ applications, IEEE Trans. Antennas Propag., 49/12, 1683-1694.

Pardo, J. R., E. Serabyn, M. C. Wiedner, and J. Cernicharo (2005), Measured telluric continuum-like opacity beyond $1 \mathrm{THz}$, J. Quant. Spectrosc. Radiat. Transfer, 96, 537-545.

Pinori, S., F. Baordo, C. M. Medaglia, A. Mugnai, and B. Bizzarri (2006), On the potential of sub-mm passive MW observations from geostationary satellites to retrieve heavy precipitation over the Mediterranean Area, Adv. Geosci., 7, 387-394.
Prigent, C., E. Defer, J. Pardo, C. Pearl, W. B. Rossow, and J.-P. Pinty (2005), Relations of polarized scattering signatures observed by the TRMM microwave instrument with electrical processes in cloud systems, Geophys. Res. Lett., 32, L04810, doi:10.1029/2004GL022225.

Prigent, C., F. Aires, and W. B. Rossow (2006), Land surface microwave emissivities over the globe for a decade, Bul. Am. Meteorol. Soc., $1573-$ 1584, doi:10.1175/BAMS-87-11-1573.

Prigent, C., E. Jaumouille, F. Chevallier, and F. Aires (2008), A parameterization of the microwave land surface emissivity between 19 and $100 \mathrm{GHz}$, anchored to satellite-derived estimates, IEEE T. Geosci. Remote, 46(2), $344-352$.

Richard, E., Cosma, P. Tabary, J.-P. Pinty, and M. Hagen (2003), Highresolution numerical simulations of the convective system observed in the Lago Maggiore area on 17 September 1999 (MAP IOP 2a), Q. J.R. Meteorol. Soc., 129(588), 543-563.

Richard, E., A. Buzzi, and G. Zängl (2007), Quantitative precipitation forecasting in the Alps: The advances achieved by the Mesoscale Alpine Programme, Q. J. R. Meteorol. Soc., 133, 831-846.

Rizzi, R., P. Bauer, S. Crewell, M. Leroy, C. Matzler, W. P. Menzel, B. Ritter, J. E. Russel, and A. Thoss (2006), Cloud, precipitation and large scale land surface imaging (CPL) observational requirements for meteorology, hydrology, and climate, Position paper, version 1.K, Eumetsat, available from http://www.eumetsat.int/Home/ Main/What We Do/Satellites/Future Satellites/Post EPS/index.htm.

Rumelhart, D. E., G. E. Hinton, and R. J. Williams (1986), Learning internal representations by error propagation, in Parallel distributed processing: Explorations in the Microstructure of Cognition, Vol. I, Foundations, edited by D. E. Rumelhart, J. L. McClelland, and the PDP Research Group, pp. 318-362, MIT Press, Cambridge.

Saunders, R. W. (1993), Note on the Advanced Microwave Sounding Unit, Bull. Am. Meteorol. Soc., 74, 2211-2212.

Saunders, R., M. Matricardi, P. Brunel, S. English, P. Bauer, U. O'Keefe, P. Francis, and P. Rayer (2005), RTTOV-8 science and validation paper, report NWP-SAF, $44 \mathrm{pp}$.

Smyth, T. J., and A. J. Illingworth (1998), Radar estimates of rainfall rates at the ground in bright band and non-bright band events, Q. J.R. Meteorol. Soc., 124, 2417-2434.

Staelin, D. H., and F. W. Chen (2000), Precipitation observations near 54 and $183 \mathrm{GHz}$ using the NOAA 15 satellite, IEEE Trans. Geosci. Remote Sens., 38(5), 2322-2332.

Staelin, D. H., A. J. Gasiewski, J. P. Kerekes, M. W. Shields, and F. J. Solman III (1998), Concept proposal for a Geostationary Microwave (GEM) Observatory, prepared for the NASA/NOAA Advanced Geostationary Sensor (AGS) Program, MIT, Lexington, Mass., p. 23.

Stein, J., E. Richard, J.-P. Lafore, J.-P. Pinty, N. Asencio, and S. Cosma (2000), High-resolution non-hydrostatic simulations of flash-flood episodes with grid-nesting and ice-phase parameterization, Meteorol. Atmos. Phys., 72, 203-221.

Wiedner, M., C. Prigent, J. R. Pardo, O. Nuissier, J.-P. Chaboureau, J.-P. Pinty, and P. Mascart (2004), Modeling of passive microwave responses in convective situations using outputs from mesoscale models: Comparison with TRMM/TMI satellite observations, J. Geophys. Res., 109 D06214, doi:10.1029/2003JD004280.

Yang, S., W. S. Olson, J.-J. Wang, T. L. Bell, E. A. Smith, and C. D. Kummerow (2006), Precipitation and latent heating distributions from satellite passive microwave radiometry. Part II: Evaluation of estimates using independent data, J. Appl. Meteorol. Climatol., 45, 721-739, doi:10.1175/JAM2370.1.

F. Aires, Laboratoire de Météorologie Dynamique, Institut Pierre-Simon Laplace/Centre National de la Recherche Scientifique, Université de Paris VI/Jussieu, Paris, France.

J.-P. Chaboureau and J.-P. Pinty, Laboratoire d'Aérologie, Université de Toulouse, Centre National de la Recherche Scientifique, Toulouse, France.

E. Defer and C. Prigent, Laboratoire d'Etudes du Rayonnement et de la Matière en Astrophysique, Centre National de la Recherche Scientifique, Observatoire de Paris, 61, avenue de l'Observatoire, 75014 Paris, France. (eric.defer@obspm.fr)

J. R. Pardo, Instituto de Estructura de la Materia - Departamento de Astrofisica Molecular e Infrarroja, CSIC, Serrano 121, E-28006 Madrid, Spain.

C. J. Walden, Space Science and Technology Department, Rutherford Appleton Laboratory, Chilton, Didcot, OX11 0QX, UK.

O.-Z. Zanifé, Collecte Localisation Satellite, Ramonville Saint-Agne, Toulouse, France. 